\title{
A Typology of Guanxi-based Governance Mechanisms for Knowledge Transfer in Business Networks of Chinese Small- and Medium-sized Enterprises
}

\begin{abstract}
Guanxi has strong implications for interactions among individuals in Chinese society. This study investigates guanxi-based governance mechanisms in the context of knowledge transfer among Chinese small- and medium-sized manufacturing firms. We analyze, in depth, qualitative interview data gathered from 78 Chinese engineers who work for Chinese smalland medium-sized die-casting manufacturers. Our findings reveal that guanxi influences the production of three forms of guanxi-enabled trust: guanxi-enabled relational trust, calculative trust, and institutional trust. By combining these forms of trust, we generate a typology of seven guanxi-based governance mechanisms for knowledge transfer - "guanxi-hu," "huibao," "lun," "gan-qing," "jiao-qing," "ren-qing," and "mianzi." We discuss the research and managerial implications of our findings.
\end{abstract}

Keywords: Guanxi; Social Exchange Theory; Social Capital Theory; Institutional Theory; Knowledge Transfer; China; Small and Medium-sized Enterprises; Network; Trust. 


\section{Introduction}

Inter-organizational knowledge transfer (knowledge transfer, hereafter) is defined as the process whereby one firm is affected by the experiences of other firms (Inkpen \& Tsang, 2005; Phelps, Heidl, \& Wadhwa, 2012). The building blocks of knowledge transfer are often formed through interpersonal interactions among employee networks across different firms (Argote \& Ingram, 2000; Argote, Ingram, Levine, \& Moreland, 2000). Weick and collaborators (Orton \& Weick, 1990; Weick, 1976) suggest that the typical structure of the network relationship is a loosely-coupled coalition, whereby individuals are connected while retaining their independence, which allows opportunism to occur. For the actors to continue collaborating with one another for a specific purpose, such as sharing and exchanging knowledge, experts suggest that governance mechanisms must exist to control actors' behaviors and interactions (Keil, Maula, Schildt, \& Zahra, 2008; Provan \& Kenis, 2008). The research on the governance mechanisms adopts two competing views. Formal governance mechanisms emphasize the establishment of contractual guidance through a legally-binding agreement (Keil et al., 2008; Provan \& Kenis, 2008), while informal governance mechanisms rely on the shared ideological values among the actors, to direct the interactions in the network relationship (Luo, Liu, Zhang, \& Huang, 2011). In the context of Chinese business networks, scholars suggest that individuals often rely more on informal governance mechanisms to control how others behave and interact in the networks (Buckley, Clegg, \& Tan, 2006; Lee \& Dawes, 2005; Tan, Yang, \& Veliyath, 2009). This means that knowledge transfer in Chinese business networks is strongly influenced by the informal governance mechanisms that are present (Buckley et al., 2006; Ramasamy, Goh, \& Yeung, 2006).

Most scholars agree that the informal governance mechanisms in Chinese business networks are manifested through the functions of "guanxi" (Chung, Yang, \& Huang, 2014; Gu, Hung, \& Tse, 2008; Luo, 2000; So \& Walker, 2013; Su, Mitchell, \& Sirgy, 2007; Tsui \& 
Farh, 1997; Yang \& Wang, 2011). Guanxi represents personal connections among individuals in Chinese society, and its functions have strong implications for interpersonal and interorganizational dynamics (Park \& Luo, 2001; So \& Walker, 2013). Researchers have long used several informal governance mechanisms derived from the functions of guanxi such as “mianzi” (e.g. Buckley et al., 2006; Zhuang, Xi, \& Tsang, 2010), "ren-qing” (e.g. Park \& Luo, 2001; Yang \& Wang, 2011), and so on, to explain how individuals should behave and interact in guanxi-based Chinese business networks. In this research, we refer to these informal governance mechanisms as "guanxi-based governance mechanisms." A close examination of the relevant literature reveals two interrelated issues that have been previously overlooked in this aspect of guanxi research: 1) there is no integrated theory to explain guanxi-based governance mechanisms in the Chinese business environment, and 2), as a consequence, our understanding of how guanxi-based governance mechanisms actually form and influence individuals' behaviors and interactions in this guanxi-based network is fragmented.

More specifically, some scholars suggest that guanxi encourages a network of cooperative relationships, and that these network contacts and relational confidences are transferable among the parties who are connected directly, or through intermediate actors (Luo, 1997; Peng \& Luo, 2000; Yang \& Wang, 2011). Others advocate that guanxi encourages the reciprocal exchange of resources (or favors) to maintain a long-term network relationship and mutual commitment (Gu et al., 2008; Park \& Luo, 2001). Yet another group of scholars asserts that guanxi represents the sociocultural norms of respect for hierarchy that emphasizes the importance of particularistic relationships and obedience to authority (Huang \& Gamble, 2011; Su et al., 2007). Due to the fact that guanxi has different functions in different situations, researchers tend to adopt different frameworks to explain guanxi-based governance mechanisms in the Chinese business environment (Yang \& Wang, 2011). As a result, our understanding of the guanxi-based governance mechanisms is scattered across 
different theoretical domains. This makes it difficult to obtain a cohesive picture of how guanxi-based governance mechanisms are formed and how they influence individuals' behaviors and interactions in guanxi-based Chinese business networks.

The goal of this article is to address these two interrelated issues by offering an integrated theory delineating the formation of guanxi-based governance mechanisms as well as the ways in which these mechanisms can influence individuals' behaviors and interactions in the context of knowledge transfer in Chinese business networks. We develop our arguments by analyzing interview data gathered from 78 Chinese engineers who work for Chinese small- and medium-sized (SMEs, hereafter) die-casting manufacturers. In doing so, we advance the guanxi research on several fronts. First, drawing on social capital theory, social exchange theory, and institutional theory to analyze our interview data, we found that the functions of guanxi facilitate the production of three forms of guanxi-enabled trust. We also found that individuals adjust their knowledge transfer practices based on the specific form of guanxi-enabled trust perceived as strong in the current knowledge networks among Chinese firms. To do so, we go beyond past research on the governance mechanisms in knowledge networks that has focused primarily on the structural features of networks (e.g. Collinson \& Gregson, 2003; Owen-Smith \& Powell, 2004; Phelps et al., 2012) by providing deeper insights on the relational aspect of interpersonal ties and interactions that facilitate the transfer of knowledge in in Chinese business networks. Second, we identified seven types of guanxi-based governance mechanisms, which play different albeit significant roles in regulating individuals' behaviors and interactions in the process of knowledge transfer in Chinese business networks. In doing so, our research contributes to the knowledge transfer literature (e.g. Argote \& Ingram, 2000; Argote et al., 2000; Muthusamy \& White, 2005; Zhao, Anand, \& Mitchell, 2005) by investigating how informal governance mechanisms formulated by the functions of guanxi affect knowledge transfer in the Chinese business network. Finally, 
we integrate these guanxi-based governance mechanisms into a theoretical model that explains how engineers in Chinese SME manufacturers can take advantage of these mechanisms to acquire important knowledge from engineers from other firms (network actors) in different circumstances. In so doing, we not only respond to the call to develop an integrated theory to explain the functions of guanxi in governing individuals' interactions in the Chinese business environment (e.g. Chen \& Chen, 2004; Yang \& Wang, 2011), but also extend the studies that investigate the influence of sociocultural forces, in a specific environmental setting, on individuals' behaviors in business networks (e.g. Alston, 1989; Inkpen \& Pien, 2006; Li, Poppo, \& Zhou, 2010; Puffer, McCarthy, \& Boisot, 2010).

\section{Theoretical Grounding}

Child and Möllering (2003) and Gao, Knight, Yang, and Ballantyne (2013) studied Chinese business networks and found that Chinese business people do not easily extend their trust to those outside their familiar social circles. Thus, they proposed that, for outsiders to enter these social circles, they should actively develop a personal rapport with the members of these circles and transfer their business practices to increase the level of trust. Tsui and Farh (1997) and Fan (2002) describe how this kind of interpersonal contact, arising as it does from personal connections, is qualitatively different from that arising from legal frameworks, and can be labeled "guanxi," a combination of two Chinese characters: "guan" meaning "to close" and "xi" meaning "link." Furthermore, many scholars propose that the functions of guanxi contribute to the formation of informal governance mechanisms in Chinese business networks (Gu et al., 2008; Luo et al., 2011; Wang, Tseng, \& Yen, 2012; Yang \& Wang, 2011). We refer to this kind of informal governance mechanism derived from the functions of guanxi as guanxi-based governance mechanisms. Prior studies suggest that the functions of guanxi influence individuals' behaviors and interactions regarding knowledge transfer in Chinese business network (Buckley et al., 2006; Ramasamy et al., 2006). 
To develop an integrated theory of guanxi-based governance mechanisms in the context of knowledge transfer, we apply three theoretical lenses from well-established theories - social capital theory, social exchange theory and institutional theory - to categorize and explain how such mechanisms influence individuals' behaviors and interactions in Chinese business networks based on two reasons. First, scholars have adopted many theories to study the functions of guanxi in Chinese business (Luo, Huang, \& Wang, 2012; Yang \& Wang, 2011). Nevertheless, not all theories have primarily been used to explain the governance mechanisms formulated by the functions of guanxi. For example, scholars use the resource-based view to explain guanxi as an important organizational resource that contributes to firms' competitive advantage (e.g. Luo et al., 2012; Tsang, 1998). Second, in order to further combine different aspects of guanxi-based governance mechanisms from different theoretical aspects into one integrated theory, we need to adopt the theories that share proximity when explaining the control mechanisms of individuals' behaviors in network relationships. Social capital theory (e.g. Gu et al., 2008), social exchange theory (e.g. Wu et al., 2006), and institutional theory (e.g. Tan et al., 2009) all emphasize the role that trust (but in different forms) plays in influencing the dynamics of behaviors and interactions among individuals in network relationships. Trust is defined as the willingness to make oneself vulnerable to the action of another party during interactions (Rousseau, Sitkin, Burt, \& Camerer, 1998; Zaheer \& Venkatraman, 1995). Synthesizing the large, but fragmented body of literature on trust, Rousseau et al. (1998) argue that there are three main forms of trust: 1) relational, 2) calculative, and 3) institutional. Relational trust is present when a relationship is formed through various causes (i.e. repeated interactions, positive experience). Calculative trust exists when the trustor perceives that the trustee intends to perform beneficial actions. Finally, institutional trust derives from the trustor's confidence that institutional factors (i.e. law, culture, etc.) can act as a deterrent to opportunist behaviors. 
Other notable theories that have also been used by scholars to explain governance mechanisms induced by the functions of guanxi such as transaction cost theory and organizational learning theory (e.g. Standifird \& Marshall, 2000; Yang \& Wang, 2011) do not share such proximity. Combining the above two reasons, we believe that our approach provides a clear theoretical foundation for interpreting how guanxi-based governance mechanisms influence individuals' behaviors and interactions in Chinese business networks.

Adler and Kwon (2002, p. 23) consolidate a variety of related definitions and express social capital as "the goodwill available to individuals or groups. Its source lies in the structure and content of the actor's social relations. Its effects flow from the information influences and solidarity it makes available to actors." Prior studies have recognized that social capital has different attributes, such as reputation, network ties, norms, shared narratives, and so on (e.g. Inkpen \& Tsang, 2005; Nahapiet \& Ghoshal, 1998; Payne, Moore, Griffis, \& Autry, 2011). Nevertheless, in relation to the influence of interpersonal and interorganizational dynamics in the network relationship, experts suggest that social capital enables actors to "bond" and "bridge" with one another (Adler \& Kwon, 2002; Davidsson \& Honig, 2003; Payne et al., 2011). The bonding aspect of social capital focusses on enhancing the strength of existing relationships (Coleman, 1990), while the bridging aspect of social capital focusses on developing new relationships (Burt, 1992, 2000). Despite their differences, both the bonding and bridging aspects of social capital emphasize that "relational trust," as a form of social capital, arises from the strength and structure of network relationships (Burt, 1992, 2000; Coleman, 1990). More specifically, previous research indicates that relational trust is developed when individuals strengthen their relationships with each other (bonding) in the existing network relationship (Coleman, 1990; Davidsson \& Honig, 2003). On the other hand, when individuals from divided communities are willing to link with one another (bridging), relational trust is developed, even though some experts suggest that such trust can 
be fragile (Adler \& Kwon, 2002; Burt, 1992, 2000; Rousseau et al., 1998). In summary, social capital theory posits that, when individuals are more willing to open up access to each other (develop new relationships) or strengthen their existing ones, then relational trust is developed in the network setting. Through the lens of social capital theory, prior studies suggest that the functions of guanxi enable individuals to extract benefits from their relationship with one another (Gold, Guthrie, \& Wank, 2002; Gu et al., 2008). Individuals can use the functions of guanxi to strengthen existing - or build new - network relationships. Such actions will lead to the improvement of trust in the network relationship which can be viewed as a form of social capital that enables Chinese business people to access important resources through their contacts (Gold et al., 2002; Lee \& Dawes, 2005; Luo, 2000).

Social exchange theory explains that the process of negotiated exchanges between two parties is subject to cost-benefit analysis and the comparison of alternatives (Cropanzano \& Mitchell, 2005; Emerson, 1976). From this theoretical perspective, an exchange relationship will only be formed when both parties consider that the existence of such a relationship is based on rational choice and is mutually beneficial (Cook, Cheshire, Rice, \& Nakagawa, 2013; Cropanzano \& Mitchell, 2005). Calculative trust, in this situation, emerges when each party perceives that the other has the intention and competence to fulfill their obligations and responsibilities in the exchange relationship (Muthusamy \& White, 2005; Shore, Coyle-Shapiro, Chen, \& Tetrick, 2009). When the calculative trust is high, both parties will have confidence that this exchange relationship is "reciprocal" (Cook et al., 2013; Cropanzano \& Mitchell, 2005). From the perspective of social exchange theory, prior studies suggest that the functions of guanxi influence the exchange of resources (or favors) and enable the exchanges between actors to be expanded from an interpersonal relationship into a broader range of social connections (i.e. a network relationship) by enforcing reciprocity in the exchange relationship (Cheung \& Gui, 2006; Wu et al., 2006; Yang, 1994). This is 
because the functions of guanxi influence both parties' behaviors to develop trust that ensures that the exchange relationship is reciprocal and mutually beneficial (Luo, 2000; Yang, 1994).

Institutional theory explains the establishment of the "rules of the game" to which individuals need to conform when engaging in specific types of activity (i.e. business transactions) in order to survive in the environment (Scott, 1994). These rules of the game consist of both formal (i.e. law) and informal (i.e. norm of behavior) constraints (Scott, 1994; Tan et al., 2009). Peng (2002) further describes how, under the conditions whereby formal constraints are neither present nor weak, informal constraints will govern interpersonal interactions. In order for the rules of the game to shape and constrain individuals' behaviors and interactions in the institutional environment, the individuals concerned need to develop trust in the institution (Peng, 2002; Peng, Wang, \& Jiang, 2008). Rousseau et al. (1998) refer to this type of trust as institutional trust. When the level of institutional trust is high, individuals will have greater confidence that everyone who is under the influence of the institution will follow the rules of the game and act accordingly (Peng, 2002; Scott, 1994). Scholars have used the institutional theory lens extensively to explain how the functions of guanxi can ultimately influence individuals' behaviors in the Chinese business environment (Huang \& Gamble, 2011; Jia \& Wang, 2013; Tan et al., 2009). More specifically, the functions of guanxi exert pressure on individuals to conform to individuals to conform to the social norms that arise from the Chinese value of social order when dealing with network relationships (Huang \& Gamble, 2011; Tan et al., 2009).

In general, the guanxi concept stems from Confucianism, which fostered the broad sociocultural aspects of collectivism manifested in the importance of maintaining harmonious relationships among individuals (Gao et al., 2013; Tjosvold, Poon, \& Yu, 2005). While studies have tracked how the functions of guanxi promote informal governance mechanisms to overcome barriers and instability in the face of challenges during the transition from a 
centrally-planned to a market-based economy (e.g. Gu et al., 2008; Luo et al., 2011; Tan et al., 2009; Wu et al., 2006; Yang \& Wang, 2011), they have provided an inadequate, integrated theory of guanxi-based governance mechanisms in the Chinese business environment. We address this deficiency in the literature by conducting qualitative research of knowledge transfer activities among Chinese SME manufacturers, and plan to interpret our data use social capital theory, social exchange theory, and institutional theory. Using these three theoretical lenses allows us to construct an integrated theory of guanxi-based governance mechanisms. These theoretical lenses provide the conceptual toolkits for developing a more in-depth understanding of how informal control mechanisms inducted by the functions of guanxi form, and how such mechanisms influence individuals' behaviors and interactions in Chinese business networks. These three theories all emphasize the role of different forms of trust in network relationship. Rousseau et al. (1998) note that these different forms of trust are not mutually exclusive, so they may overlap and constitute a combination of several forms. As we uncover how the functions of guanxi influence individuals' behaviors and interactions in different situations in Chinese business networks and how trust plays role in these situations, we can further combine relevant concepts derived from our findings to develop an integrated theory to explain guanxi-based governance mechanisms.

\section{Research Context}

Following the series of economic reforms post-1978, primarily supported by its manufacturing industry, the Chinese economy has experienced extensive growth. Lüthje (2004) suggests that, due to the relatively low cost of labor and government incentives, China has become one of the most important manufacturing bases in the world, contributing substantially to the industrial global supply chain networks. Recent research has found that many Chinese manufacturers fulfill not only production and physical distribution functions, but also design and engineering functions, in the process of introducing new products and 
modifying their existing products worldwide (Eloot, Huang, \& Lehnich, 2013; Lüthje, 2004). To improve their capacity for innovation, Chinese manufacturers, like any other firm, require access to knowledge resources. Firms can access important knowledge from both internal and external sources to fuel their innovation activities (Davidsson \& Honig, 2003; Kato, Okamuro, \& Honjo, 2015; Phelps et al., 2012). Human capital, defined as the skills and knowledge that individuals (firms' employees) acquire from their education, prior experience and any other source, is the primary internal source of knowledge (Davidsson \& Honig, 2003). The literature suggests that human capital increases firms' ability to engage in innovation and exploit business opportunities (Kato et al., 2015). Knowledge transfer, on the other hand, represents the primary external source of knowledge. Research suggests that knowledge transfer allows Chinese firms to access external sources of knowledge and develop their innovation capacity (Inkpen \& Tsang, 2005; Zhao \& Anand, 2009).

The research target for our study is Chinese manufacturers. Given that most Chinese manufacturers are SMEs (Biz China, 2013; Eloot et al., 2013), in order for them to compete with large firms and other SMEs, we argue that the primary source of knowledge for the purpose of innovation is knowledge transfer, based on two reasons. First, SMEs usually lack the necessary human capital to fuel their innovation activities continuously, given their size and limited financial resources (Collinson \& Gregson, 2003; Etemad \& Lee, 2003). Second, research suggests that emphasizing the use of networks to share resources (including knowledge) for survival and to gain an edge over one's competitors is a typical Chinese organizational behavior (Luo, 2000; Zhuang et al., 2010). Researchers report that interpersonal interaction plays an important role in knowledge transfer in China. For example, the studies of the Chinese automotive industry conducted by Zhao and colleagues (Zhao et al., 2005; Zhao \& Anand, 2009) conclude that hands-on experience and employees' interpersonal interactions with others, both internally and externally, also play an important role in 
knowledge transfer. According to prior research, this kind of interpersonal interaction in the Chinese business environment is highly influenced by the functions of guanxi (Luo, 2000; Park \& Luo, 2001; Ramasamy et al., 2006). It is this type of governance mechanism, derived from the functions of guanxi (guanxi-based governance mechanisms), that influence individual behaviors and interactions in the aspect of knowledge transfer among Chinese SME manufacturing firms, which constitutes the focus of our study.

\section{Research Method}

Qualitative research appears to be particularly suited to the study of the inherent complexity of guanxi-based governance mechanisms from a multi-agent perspective, as it enables the close observation of organizational routine and decision making (Blumberg, Cooper, \& Schindler, 2005). The collection of data of sufficient quality for this study required the identification of appropriate informants from appropriate sources to offer us a wider range of experiences and perspectives for our research topic. Among the various Chinese manufacturing sectors, we choose to focus on the "die-casting" industry. Die-casting is a process of forcing molten metal under high pressure into reusable steel molds, which enables the manufacturer to produce complex shapes with a high degree of accuracy and repeatability of the engineering parts (NADCA, 2013). The designing of die-casting parts is a highly complex process, requiring experience, domain knowledge, and problem-solving skills, and always involves a series of decisions, from the selection of the material, engineering structure (mold and part) and machinery technique, to surface finishing and so on (Choi, Kwon, Park, Kim, \& Kim, 2002; Lee \& Luo, 2002). Die-casting manufacturers require access to external sources of knowledge to improve their capacity for research and development.

The chosen data collection method is the in-depth semi-structured qualitative interview. We used the snowball sampling method (Biernacki \& Waldorf, 1981) to collect interview data from 78 engineers who have been involved in the knowledge transfer process (see 
Appendix 1). The interviews can be divided into two stages. The first stage of the interview process involved a discussion about the informants' involvement in knowledge transfer. In the second stage, open-ended questions explored how the informants acquire the knowledge needed to accomplish their professional tasks, what the exchange patterns are, what the exchange guidelines are, and how these guidelines are formulated and enforced. We asked the interviewees to describe the reasons and thought processes behind their answers.

All of the informants felt that the interview topic touched on a sensitive aspect of their business and position, so none was willing to be tape-recorded. Moreover, the majority of the informants asked for the interviews to be conducted in a private, informal environment outside their company (i.e. a restaurant), where they felt more comfortable about expressing their views about the interview topics. To compensate for such constraints, we took the following steps to gather as much information as possible. Firstly, we took detailed notes and asked the informants to confirm their key points during the interviews. Second, toward the end of each interview, we spent some time going through the notes with the interviewee to ensure that we had recorded their narrative correctly. Finally, if we had any queries, we contacted the interviewee by phone or email to request clarification. In total, we re-contacted 31 informants. A typical query involved asking them to supply more information on their responses provided during the interview. For example, we asked one of our interviewees (Engineer 24) to explain the exact processes by which he used the functions of guanxi (before and afterward) to persuade his friend (an engineer from another firm) to share his knowledge regarding the surface treatment temperature required for a specific material. Our informants appeared happy to assist with this, on condition that all of our phone calls and emails were directed to their personal phone numbers and email accounts during non-office hours.

Our analysis followed the established techniques and procedures for grounded theorybuilding (Corbin \& Strauss, 2014; Locke, 2001). The first step was to translate our notes from 
Mandarin into English. The second step was the coding, and we used NVivo software to assist with this in order to reduce the confusion inherent in the data analysis. In this research, we wish to explore how interpersonal interactions that are influenced by the functions of guanxi can contribute toward knowledge transfer. Thus, we focus on understanding how individuals interact with each other to facilitate inter-organizational knowledge transfer and the role of guanxi-based governance mechanisms in influencing such interactions. To answer our research question, we analyze the data in two stages. In the first stage, we explored how different forms of trust derived from different theoretical foundations (social capital, social exchange and institutional theories) are formed through the influence of guanxi functions on interpersonal interactions. Thus, we coded individual interviews with regard to perceptions of relational, calculative, and institutional trust that were generated by the use of guanxi functions to influence interpersonal interactions, based on the descriptions offered by the informants. Relational trust emerged from what the respondents said regarding their thoughts and feelings when they were evaluating trust or trustworthiness based on a relationship formed through the use of guanxi (based on social capital theory). Calculative trust was coded in terms of what the respondents said regarding their thoughts and feelings when evaluating trust or trustworthiness based on accessing other actors' intentions and competence with regard to returning favors from the aspect of guanxi (based on social exchange theory). Institutional trust was coded in terms of what the respondents said regarding their thoughts and feelings when evaluating trust or trustworthiness based on conforming to the social order promoted by the functions of guanxi in relation to the hierarchy of social relationships (based on institutional theory). These formed our first-order codes (see Appendix 2). We then compared the coded documents and discussed the emerging potential conceptual patterns. We searched for first-order codes that could be collapsed together to produce a set of first-order categories. We then examined the link among first- 
order categories, clustered them to create second-order themes, and then grouped similar second-order themes together to produce a more general theoretical dimension. In total, three dimensions emerged strongly here: guanxi-enabled relational trust, guanxi-enabled calculative trust, and guanxi-enabled institutional trust.

In the second stage of the data analysis, we wished to explore how knowledge derived from guanxi-directed interpersonal interactions was shared among firms. To do so, we first divided our coded documents into three groups, according to the three dimensions (guanxienabled relational trust, guanxi-enabled calculative trust, and guanxi-enabled institutional trust) identified in our first-stage analysis, then re-coded the interviews for each group of documents according to the phrases, terms, and descriptions that the participants offered, all of which revolved around the construct of knowledge transfer. Such descriptions include what the respondents said regarding their thoughts and feelings and what they did (or did not do) in regard to sharing knowledge with actors from other firms. Following the same procedure employed in the first stage of the analysis, we looked for links among our codes to generate the first-order categories and then second-order themes to produce an aggregate theoretical dimension that we referred to as the "content of knowledge transfer." Lastly, we combined our findings from the two stages of the analysis to develop a cohesive picture regarding guanxi-based governance mechanisms for knowledge transfer.

At the end of our data analysis, we took two additional steps to help to ensure the trustworthiness of our data. First, both authors followed the same steps to analyze the data independently. We then assessed and discussed each other's codes until we achieved a strong agreement and there were no discrepancies between our conclusions. Second, we invited an independent person to act as an external coder, and to code a random sample of 20 interviews (roughly 25\%) using our category template to establish inter-coder reliability. Dividing the number of coding agreements by the total number of coding agreements and disagreements 
suggested that there was a reliability rating of $96.67 \%$. We discussed the remaining differences with this external coder and reached a consensus. Figure 1 illustrates our final data structure and shows the connections among them. We present summaries of the interview data in our discussions and provide representative quotes in Tables 1 and 2.

\section{"Insert Figure 1 about Here" \\ "Insert Table 1 about Here" \\ "Insert Table 2 about Here" \\ Findings and Analysis}

We found that the functions of guanxi promote three forms of guanxi-enabled trust, which influences knowledge transfer in Chinese business networks (see Figure 1). These three forms of guanxi-enabled trust and combination thereof can lead to the formation of seven types of guanxi-based governance mechanisms, which play a different, significant role in governing individual behaviors in Chinese business networks (see Figure 2).

"Insert Figure 2 about here"

\section{Guanxi-enabled Relational Trust and the Guanxi-hu Mechanism}

Our analysis suggests that individuals use the functions of guanxi to build relationships that make it possible to formulate relational trust in Chinese business networks (see Figure 1). We speak of this type of trust as guanxi-enabled relational trust, because it is derived from the functions of guanxi that make individuals feel confident and willing to enter into a relationship with a specific partner. As Figure 1 shows, we found that employees use the functions of guanxi to form a relationship with others and then use the trust developed from such relationships to gain access to the knowledge that they require to complete their work-related tasks. This finding illustrates perfectly the phrase, "who you know" affects "what you know" (Nahapiet \& Ghoshal, 1998), and explains the importance of the development of guanxi-enabled relational trust in permitting the transfer of knowledge. 
Within Chinese business networks, our data indicate that the determinant of the effectiveness of the knowledge transfer process is based on the actors' direct or indirect affiliation with guanxi-hu (see Figure 1). "Hu" is a unit of measurement that can refer to "a person," "an organization," or even "a government department" in Chinese society (Luo, 2000; So \& Walker, 2013). Given that this study aspires to understand interpersonal interactions that contribute toward knowledge transfer, therefore, the representation of "hu" in our study is "a person." A guanxi-hu refers to a highly-connected individual who occupies a focal point in one's guanxi-based network (Chen \& Chen, 2004; Park \& Luo, 2001). A guanxi-hu can represent either an actor who possesses knowledge or a broker who helps the employees to establish a relationship with an actor who possesses knowledge.

Gold et al. (2002) suggest that the concept of guanxi is closely linked to the concept of social capital in the Chinese context. In relation to the bonding aspect of social capital (Coleman, 1990), we found that individuals use the functions of guanxi to improve and maintain the strength of their relationships with important network contacts, which leads to the enrichment of trust in the network relationships. Trust emerges when the employees and the guanxi-hu develop a strong relationship; in turn, this makes the guanxi-hu more willing to help the employees to access important knowledge due to the increased confidence in this interpersonal relationship. This reflects the suggestions from an interviewee (Engineer 7):

"My friend knows many people in this industry [guanxi-hu]. If I want to know something, I will also contact him. I trust [guanxi-enabled relational trust] him who will always pass me the right information because over the past few years we have built strong guanxi with each other."

In order to establish this trusting (guanxi-enabled relational trust) relationship with the guanxi-hu, we found that employees spent a long time in a working relationship with the guanxi-hu to strengthen their guanxi-enabled connections (see Table 1). This is in line with Rousseau et al. (1998) suggestion that relational trust derives from repeated interactions between the parties over time. We also found that, in Chinese business networks, employees 
can develop trusting relationships with a guanxi-hu through having a connection with another (middle man) guanxi-hu, who has already established guanxi-enabled relational trust with the first guanxi-hu. From the bridging social capital perspective (Burt, 1992, 2000), this guanxihu (middle man) plays a brokerage role in helping employees to form bridges with external networks, which leads to the development of a trusting (guanxi-enabled relational trust) relationship. To accomplish this, we found that guanxi-enabled relational trust can be passed from one relationship to another, as one interviewee indicates (Engineer 76):

"If my friend cannot answer my question, he will always introduce me to someone he has strong guanxi with and who know the answers to my question. [...] the reason that this person is willing to help me is because he trusts my friend [guanxi-hu], so he begins to trust me."

Although only a low level of guanxi-enabled relational trust is transferred from one relationship to another, it is still sufficient to allow employees to access the knowledge of other actors from different firms. In other words, guanxi influence is transferable among parties or from an individual to a corporation, because an individual's guanxi can be viewed as his/her extended representation that others need to treat with respect (Gu et al., 2008; Park \& Luo, 2001).

Along with the expansion of network contacts driven by the guanxi-hu, we also found that the that he or she can help employees to attend specific events in exclusive locations, where the actors who possess important knowledge feel more comfortable about interacting and sharing their knowledge with them (see Figure 1). Information grounds are places where people feel comfortable about sharing their knowledge and information in specific locations or environments (Fisher \& Naumer, 2006). We found that the transfer of knowledge often takes place during specific events at exclusive locations, such as private dinners, games of golf, and ma-jiang matches. In order for employees to participate in these events, they usually need a select group of individuals (guanxi-hu) to accompany them (see Table 1). The reason why the actors who possess knowledge are more willing to share important knowledge with 
one another is that they feel that anyone who participates in such an event can be trusted (guanxi-enabled relational trust), as suggested by an interviewee (Engineer 39):

"Not everyone can be invited here [i.e. private club]. The individuals who get invited are in our inner circle. We trust everyone in our inner circle."

This finding is consistent with the network membership view of social capital, whereby actors' membership of a social network enables them to develop trust (as a form of social capital) of each other, which leads the actors to access the resources within that social network (Bourdieu, 1986; Portes, 1998). Our findings suggest that employees who are invited to participate in these specific events at exclusive locations are considered trustworthy members (of this social network) and that the guanxi-hu plays a critical role in bringing them to the event (see Table 1). Consequently, the actors who possess knowledge at such events are willing to share important knowledge with this (middle man) employee.

To summarize, our analysis suggests that the development of guanxi-enabled relational trust and its function in promoting knowledge transfer can be illustrated in two domains: network contacts and information ground (see Figure 1). Collectively, these two domains highlight the importance of bonding with a guanxi-hu, so that he/she can pass important knowledge to employees or help employees to bridge with other actors within the inter-organizational knowledge web. Such a mechanism focusses on the salience of guanxienabled relational trust and the important role played by the guanxi-hu, and dictates how employees from different firms interact with one another to enable knowledge transfer from firm to firm. We refer to this guanxi-based governance mechanism as the "guanxi-hu mechanism," under which a high degree of interpersonal interactions with regard to knowledge transfer occur once the guanxi-hu is in place (see Figure 2). Hence:

Proposition 1: The use of guanxi functions to establish network contacts and information ground that can promote guanxi-enabled relational trust, which leads to the establishment of the guanxi-hu mechanism to govern knowledge transfer toward collaborative knowledge accessing. 


\section{Guanxi-enabled Calculative Trust and the Huibao Mechanism}

Calculative trust, considered the central premise of social exchange, represents the silent mutual contract in which one party offers resources to another party with a high level of confidence that the latter will later return the equivalent value in one form or another (Cropanzano \& Mitchell, 2005). According to our data analysis, we identify that the second type of trust - "guanxi-enabled calculative trust" - plays a critical role in governing knowledge transfer. The development of such trust involves the exchange of favors. Our finding suggests that it is important for employees to recognize the costs and benefits involved in such knowledge transfer (see Table 1). Social exchange theory predicts that individuals will calculate the overall costs and rewards of engagement in a collaborative relationship and decide whether to continue or terminate it (Cropanzano \& Mitchell, 2005; Emerson, 1976). On the one hand, an actor who possesses important knowledge is rewarded by a promise of something in return. On the other hand, an employee who receives the information makes this promise to show his/her appreciation, as well as to express reciprocity. An interviewee suggests (Engineer 68):

"Returning the favors is very important. I usually send him a gift after I have asked something [i.e. information] from him. [...] it shows my appreciation and keeps this mutually beneficial relationship going. [...]."

The process operates such that, if an employee uses the functions of guanxi to approach an actor for a favor during knowledge transfer, that employee is obliged to return the favor when the actor initiates a similar exchange later. When the individuals who wish to engage in a knowledge exchange relationship face a situation whereby the formal structure of the legal framework(s) is still under development (as currently the case in China), trust emerges when they feel confident (due to the functions of guanxi) that their exchange partner has the intention and competence to return the favor (see Figure 1). Yang (1994) describes how this form of trust, derived from the functions of guanxi, obligates an individual who receives a 
favor to return in the spirit of the exchange relationship. We argue that such trust can be considered guanxi-enabled calculative trust because it derives from the reciprocal exchange of favors in the context of the improvement and preservation of guanxi.

The guanxi-enabled calculative trust will diminish when individuals refuse to return favors in the network relationship. For actors to be willing to share their knowledge with each other in the network environment, they need to ensure that they have confidence in each other and that no one will take advantage of anyone else. Otherwise, this 'free-rider' problem will reduce the level of trust in the network relationship (Crouch, 2005), whereby individual actors desire to gain benefits from the social network without contributing any favors in return. In this situation, all of the actors within the network can work together collectively to oppose such unethical behavior. Based on our data analysis, we found that, if an employee does not return the favor of the actor, the actor who has passed on knowledge to such an employee will tell everyone in his/her network to boycott this particular individual from any future knowledge transfer relationship (see Figure 1). This employee can expect to lose many future opportunities to cooperate in a knowledge transfer relationship with this actor and everyone else in his/her immediate network as suggested by an interviewee (Engineer 48):

"There is no way that I will share information with someone again, if he/she does not return the favors. [...]. I will even spread the word and tell others about what he/she had done. No one will ever help him/her."

In general, we found that guanxi-enabled calculative trust is built upon the use of guanxi to ensure favor-exchange and to boycott free-riders. This is consistent with the suggestions from Park and Luo (2001) that individuals will not be viewed as trustworthy in any other social relationship if they fail to return the favor. We found that these two domains highlight the importance of reciprocity in relationships due to the influence of guanxi. We refer to this as the huibao (reciprocity in Chinese is bao or huibao) mechanism, under which, 
when knowledge transfer occurs, after the employee receives the favor (the transfer of knowledge), he/she should return it when the opportunity arises (see Figure 2). Hence:

Proposition 2: The use of guanxi functions to ensure favor-exchange and boycott freeriders can promote guanxi-enabled calculative trust, which leads to the establishment of the huibao mechanism to govern knowledge transfer toward reciprocal knowledge exchange.

\section{Guanxi-enabled Institutional Trust and the Lun Mechanism}

According to our data analysis, we argue that the third form of trust is "guanxienabled institutional trust," which helps to shape individuals' behaviors and interactions when sharing knowledge among people of different social rank based on the specific institutional arrangements in China. Institutional theory predicts that individuals will conform to the behavioral norm (the 'rules of the game') in the institutional environment (Peng, 2002; Peng et al., 2008). Our results suggest that the behavioral norm in Chinese business networks is that the strength of the relationship derived from guanxi is unequal (the hierarchy of the social relationship) and highly subject to the Chinese value of social order in determining an individual's status in the social relationship (see Table 1). This reflects Chen (1994) finding that a Chinese individual divides his/her social relationships into several circles and that these different circles imply the different statuses of individuals in such relationships. In the context of our study, we found that individuals tend to feel obliged to provide help, and have more confidence in others who are close to them in the social relationship (see Figure 1). When attempting to obtain important knowledge from their network relationships, employees tend to start with the actors with whom they have a close social relationship, particularly a common background and family connections. An interviewee remarks (Engineer 47):

"If I do not know how to do it [design new product features], I will first consult with my cousin [an engineer from other firm] before I ask everyone else I know."

Qing (2008) suggests that the structure of Chinese society originated from and was supported by personal relationships, as applies to any other societies which form different layers of 
network circles which impact on the effectiveness of the knowledge flow. Our analysis suggests that employees who share a similar background and family connections with actors are considered to have a high status in this social relationship. This echoes Redding and Wong (1986) suggestion that, from the Chinese perspective, relationships can be viewed as lying at the center of a series of concentric circles, such as a family member, close relative, distant relative, and so on, with the degree of closeness between these individuals varying according to their proximity to the center. Therefore, they have better access to important knowledge in the context of knowledge transfer.

By observing the nature of status hierarchy in the social relationship, we found that the strength of the relationship decreased in the following order of the individual's status in the social relationship: relatives (first order), friends (second order), and individuals from the same region/classmates (third order). Such relationship prioritization order (derived from guanxi) forms the foundation for guanxi-enabled institutional trust and determines the willingness of the actors to supply the knowledge requested by the employees (see Figure 1). This general order reflects the model of the hierarchy of social relationships (such as rulersubject, father-son, husband-wife, brother-brother and friend-friend) in Chinese society (Chen \& Chen, 2004; Cheung \& Gui, 2006; Su et al., 2007). More importantly, our findings reflect this notion, as people will be more likely to pass on important knowledge to someone who is close to them in terms of their status in the social cycle, and so the employees develop a high level of confidence (guanxi-enabled institutional trust) that they will receive knowledge if they are within the inner cycle of the social relationship. For individuals who are distant from the center of the (guanxi) circle, Su et al. (2007) indicate that they may be less affectionately attached to the guanxi relationship and less motivated to share their resources with individuals who stand at the center of the guanxi circle, and vice versa. Thus, the functions of guanxi help to install individuals' trust that the hierarchy of social relationships matters, and 
that everyone should follow the rules of the game to offer differential treatment according to individual status hierarchies during interpersonal interactions; this in turn will reduce uncertainty and ensure constancy (Chen \& Chen, 2004; Tsui \& Farh, 1997).

Since such institutional influence is strong in Chinese society, we found that individuals often struggle due to a clash between their commitment to their employer and their commitment to those with those with high status in their social cycle. An interviewee suggests (Engineer 8):

"It is hard for me to decide whether to pass on the knowledge [a specific manufacturing process] to my uncle [engineer from another firm]."

Agent theory predicts that, where ownership and control are separated, an agent's interests can potentially conflict with those of the principal of the firm and so agents may choose to pursue strategies and activities that benefit them at the expense of the principal (Eisenhardt, 1989). Although, in the context of our study, our informants (i.e. engineer - agent) do not have control over the firm, they do pursue activities that may benefit themselves (i.e. in maintaining harmonious interpersonal relationships) at the expense of the firm. As Figure 1 shows, guanxi-enabled institutional trust emerged when the actors were willing to transfer important knowledge at the request of an employee who is in the inner circle of the actor's social relationship without the agreement of the employer (who is often considered as being in the outer circle of the actor's social relationship).

Overall, we argue that guanxi-enabled institutional trust is built upon the hierarchy of social relationships in Chinese society. Our findings highlight that that the practice of honoring such trust, that determines the destination of the knowledge flows in the context of knowledge transfer, falls into three domains: the social cycle, relationship prioritization, and conflict of interest. We refer to this as the "lun mechanism" (the Chinese model of relationship hierarchy), under which the employee will receive preferential treatment from 
the actor if he/she is considered to have a high status in the social cycle with the actor, when requesting the transfer of knowledge (see Figure 2).

Proposition 3: The use of guanxi functions to endorse social cycle, relationship prioritization and conflict of interest can promote guanxi-enabled institutional trust, which leads to the establishment of the lun mechanism to govern knowledge transfer toward hierarchical knowledge sharing.

\section{Qing Mechanisms: Jiao-qing, Ren-qing, and Gan-qing}

In the above discussions, we identify three forms of guanxi-enabled trust that evolve under the influence of guanxi functions. The presence of each form of guanxi-enabled trust can foster the production of a particular type of guanxi-based governance mechanism (guanxi-hu, huibao, or lun mechanism) to govern individuals' behaviors and interactions that are the building blocks for knowledge transfer within Chinese business networks. We also found that having a high degree of any two of these three forms of guanxi-enabled trust present can produce a further three advanced types of guanxi-based mechanism: Jiao-qing, ren-qing and gan-qing (see Figure 2). We refer to these as "qing" mechanisms, thereby echoing Chen and Chen (2004) view that "qing" (a Chinese concept) by itself means "feeling", but that it takes on different meanings when placed in different contexts to explain how well a given guanxi functions to satisfy the mutual affective and instrumental needs of parties in dissimilar situations.

The "jiao-qing mechanism" was associated with a high degree of both guanxi-enabled relational trust and guanxi-enabled calculative trust (see Figure 2). Chen and Chen (2004, p. 314) suggest that jiao-qing pertains to "the sense of obligation and indebtedness that result from social and economic transaction" over a long period. Under the jiao-qing mechanism, we find that the transfer of knowledge between an employee and an actor is governed by the degree of indebtedness involved as suggested by an interviewee (Engineer 27):

"I will not hesitate to help [pass knowledge to] my closest friend. He has helped me a lot since I have come here. I would never be who I am without his help." 
In order for the jiao-qing mechanism to work, an employee needs first to accumulate favors by buying his/her way (in the form of effort, money, services, and so on) into the relationship with the actor (often the guanxi-hu) by increasing the level of their indebtedness in this relationship. From our observation, we found that an employee who attempts to enter into the relationship with an actor needs to contribute at an earlier stage (or even for a long time) in order to first establish trust (guanxi-enabled relational trust) and then, subsequently, receive the transfer of knowledge (see Table 2). We reason that this allows the actor to develop a sense of acceptance about a new (i.e. employee), trustworthy (guanxi-enabled calculative trust) exchange partner. By showing that they are willing to pay the price up-front, the employees, subsequently, demonstrate to the actors that they will not take advantage of this relationship but can reciprocate favors.

Proposition 4: The simultaneous presence of guanxi-enabled relational trust and guanxi-enabled calculative trust will lead to the establishment of the jiao-qing mechanism to govern knowledge transfer.

Secondly, the "ren-qing mechanism" had a high degree of both guanxi-enabled calculative trust and guanxi-enabled institutional trust (see Figure 2). According to Yang and Wang (2011, p. 493), the term ren-qing refers to "exchanges of favors, both emotional and economical, following certain social norms and behavioral rules." Our analysis suggests that such "social norms and behavioral rules" in the context of research are highly related to the relationship priority in Chinese business networks (Engineer 50).

"I pass a lot of information [i.e. manufacturing knowledge] to my brother-in-law not only because he is my relative and I know that I can trust him, but also because he will readily return the favor to me, if I need his help [knowledge sharing]."

Gouldner (1960) indicates that the reciprocity norm applies universally to all in stabilizing the social system and interpersonal relationships. The key difference between reciprocity in Western and Chinese networks lie in the fact that the latter often links people across uneven ranks, "with the weaker party calling for special favors without an equal level of reciprocal 
obligation" (Park \& Luo, 2001, p. 457). Under the ren-qing mechanism, we found that the transfer of knowledge is not necessarily equally reciprocal (deriving from guanxi-enabled calculative trust) but is subject to the hierarchy of social relationships (deriving from guanxienabled institutional trust). When the exchange takes place across different ranks, it tends to favor the weaker partner. The findings also reflect the suggestions made by Alston (1989), that the power of the weaker is usually based on the Confucian principle of family devotion, in which family ties demand an exchange of aid. As displayed in our example, the weaker party obtains more benefits from the unequal reciprocation (see Table 2). However, this does not mean that all family relationships are based on cooperation. We also acknowledge the existence of conflict and disagreement within family relationships. Nevertheless, based on the data obtained from our sample, having a family relationship with a stronger party appears to benefit the weaker party.

Proposition 5: The simultaneous presence of guanxi-enabled calculative trust and guanxi-enabled institutional trust will lead to the establishment of the jiao-qing mechanism to govern knowledge transfer.

Finally, the gan-qing mechanism is based on a high degree of guanxi-enabled relational trust and guanxi-enabled institutional trust (see Figure 2). The term "gan-qing" refers to an emotional attachment among the parties to a network (Chen \& Chen, 2004). Under the gan-qing mechanism, we find that the transfer of knowledge between employees is based on the quality of the relationship in terms of loyalty and solidarity. Our findings suggest that the transfer of knowledge tends to take place between parties with strong "ganqing" (see Table 2). Having strong gan-qing means that the parties enjoy a reliable, dependable relationship with each other. Thus, guanxi-enabled relational trust is high in this context. At the same time, both parties also have positive expectations about each other's intentions, because they are both in the inner circle of the social relationship (i.e. family members), that that instills confidence in them (guanxi-enabled institutional trust) that both 
sides will follow the Chinese value of social order to confer preferential treatment to each other. The concept of gan-qing suggests that trust is derived from both the relationship interaction and the Chinese value of social order. An interviewee's response reflects this point of view (Engineer 42):

"I trust my cousin. We grew up together and helped each other when we come to this city. He and his family are the only close relatives I have in this city. Of course, I will help him [pass knowledge] and treat his request as my priority."

The employees find that individuals with whom they have strong gan-qing are more loyal toward them and less likely to take advantage of them. Hence, employees feel more confident about engaging in activities related to the transfer of knowledge with this type of individual.

Proposition 6: The simultaneous presence of guanxi-enabled relational trust and guanxi-enabled institutional trust will lead to the establishment of the jiao-qing mechanism to govern knowledge transfer.

\section{The Mianzi Mechanism}

The Mianzi (face or Lian) mechanism consists of a high degree of all three types of guanxi-enabled trust. Mianzi refers to "the recognition by others of an individual's social standing and position" (Buckley et al., 2006, p. 276). An interviewee suggests (Engineer 67):

"In my definition, the mianzi is the ultimately currency that we can have in our industry. Having mianzi, and having someone who has mianzi and who is willing to support you, you can get a lot of help [i.e. transfer of knowledge]. It is because everyone respects and is willing to help someone with big [great] mianzi"

Park and Luo (2001) suggest that mianzi is determined by an individual's position, credibility, honesty, reputation, power, income, and/or network. As Figure 2 shows, the features of the mianzi mechanism can be delineated by the combination of guanxi-enabled relational trust, guanxi-enabled calculative trust, and guanxi-enabled institutional trust. Through the lens of institutional theory, that emphasizes the constraints that structure human interactions (Peng, 2002; Scott, 1994; Tan et al., 2009), mianzi represents the network members' collective confidence (guanxi-enabled institutional trust) that all members will have positive intentions and offer preferential treatment during the interpersonal interactions with the specific actors 
who have "mianzi." Our analysis suggests that the mianzi mechanism usually involves the focal party providing actual benefits (i.e. knowledge) and the recipient, in return, providing nothing immediately, due to the recipient's or other party's (whom the focal party respects) mianzi (see Table 2). From the lens of social exchange theory, that focusses on reciprocal exchange (Cook et al., 2013; Muthusamy \& White, 2005; Shore et al., 2009), mianzi can be considered as something that has value and which can be factored into the cost-benefit analysis to determine the level of reciprocity in the exchange relationship. According to our data analysis, one party can have confidence (guanxi-enabled calculative trust) that the other party will honor the value of mianzi and reciprocate with services (see Table 2). This means that mianzi is like social currency; not only can it be used in exchange for tangible benefits, but it can also be transferred and combined to exchange for higher-priced favors.

Finally, from the lens of social capital theory, that highlights the importance of bonding and bridging with one another (Adler \& Kwon, 2002; Davidsson \& Honig, 2003; Payne et al., 2011), mianzi represents the network members' collective acknowledgment of the people's status (i.e. guanxi-hu) in the social network, and can be used to leverage the process of the bonding of the actors as well as bridge between external networks in order to gather knowledge resources. In this situation, guanxi-enabled relational trust emerged when actors felt that they need to honor their own relationship with the middle man (i.e. the guanxihu with whom the employee has bonded or who has helped the employee to bridge the relationship with this actor) and respond to the employee's requests with regards to knowledge transfer (see Table 2). Using this aspect of mianzi, an employee can access important knowledge from many actors in the social network, even though the employee is considered to have a lower status in the relationship hierarchy and has less to offer in return to the actors who shared the knowledge with him/her. Furthermore, the guanxi-hu who helps the employee (by allowing him/her to use the guanxi-hu's mianzi to access the knowledge of 
the other actors) usually demands very little in return because of his/her social status in the hierarchical relationship due to the influence of Chinese culture. This finding is consistent with Lin's conclusion (e.g. Lin, Ensel, \& Vaughn, 1981; Lin, 2002) that people from the top of a social hierarchy have less to gain. It also reinforces Putnam (1993) and Bourdieu (1986) views that the influence of social capital often combines with a country's culture and operates as a salient governance mechanism as part of an informal institution that affects the interpersonal interactions in such country. In combining the above discussions, we propose:

Proposition 7: The simultaneous presence of guanxi-enabled relational trust, guanxienabled calculative trust, and guanxi-enabled institutional trust will lead to the establishment of the mianzi mechanism to govern knowledge transfer.

\section{Discussion and Conclusions}

To develop their intellectual advantages, it has been widely reported that firms access new, external sources of knowledge via knowledge transfer in business networks (Collinson \& Gregson, 2003; Muthusamy \& White, 2005). By analyzing 78 interviews from Chinese engineers worked die-casting SME manufacturers, we argue when knowledge transfer is based on the interactions of individuals, the sociocultural forces in different environmental settings (e.g. country, organization) that guide interpersonal interactions in such settings will start to play an important role in influencing the process of knowledge transfer. Accordingly, our research makes three important theoretical contributions to theorizing about the trustbehavior linkage in the knowledge network and governance mechanisms in knowledge transfer, as well as theories of sociocultural forces that influence individuals' interactions and behaviors in specific network environmental settings.

\section{Theoretical Contributions}

Firstly, our research contributes to governance mechanisms in the knowledge network literature (e.g. Collinson \& Gregson, 2003; Owen-Smith \& Powell, 2004; Phelps et al., 2012). As we argue up-front, existing research suggests that interpersonal interactions in knowledge 
networks play an important role to improve the competitive advantage for Chinese firms (So \& Walker, 2013; Zhao \& Anand, 2009) and the functions of guanxi have different effects on interpersonal interactions in Chinese society (e.g. Chen \& Chen, 2004; Luo, 1997; Peng \& Luo, 2000; Yang \& Wang, 2011). In this research, we have shown that the interpersonal interactions in Chinese business knowledge networks are shaped by three different forms of guanxi-enabled trust (guanxi-enabled relational trust, guanxi-enabled calculative trust, and guanxi-enabled institutional trust) derived from the functions of guanxi from three different theoretical domains (social capital theory, social exchange theory, and institutional theory). As a result, an individual constructs three sets of primary behavioral patterns (collaborative knowledge accessing, reciprocal knowledge exchanging, and hierarchical knowledge sharing) to transfer knowledge in the Chinese business network. These findings are important to knowledge networks research that largely focusses on exploring the influence of the structural features of a network. We extend this line of research by providing a deeper understanding of how the relational aspect of networks (such as trust) influences the knowledge transfer methods in Chinese business networks. Our results show that the attention to how individuals interact with one another in responding to the presence of a specific form of guanxi-enabled trust is important for understanding individuals' behavioral patterns in knowledge transfer. We throw light on these dynamics by identifying the relationship between different forms of guanxi-enabled trust and individuals' corresponding knowledge transfer behaviors in knowledge networks formulated among Chinese SMEs.

Secondly, the current research contributes to our understanding of knowledge transfer (e.g. Argote \& Ingram, 2000; Argote et al., 2000; Zhao et al., 2005). In this study, we identify seven different guanxi-based governance mechanisms ("guanxi-hu," "huibao," "lun," "ganqing," "jiao-qing," "ren-qing," and "mianzi”) that affect knowledge transfer among individuals from Chinese SMEs. These findings have important implications for knowledge 
transfer processes. We demonstrate that when a specific guanxi-based governance mechanism is strong in a particular setting, individuals' behaviors and interactions regarding knowledge transfer will be altered to conform with this governance mechanism. Given that the patterns of behavior during knowledge transfer have to conform with the dominant guanxi-based governance mechanism in the environment, individuals can take advantage of the situation by engaging in knowledge transfer activities in Chinese business networks when the guanxi-based governance mechanism is working in their favor. The current research extends the prior works in knowledge transfer by showing how these seven types of guanxibased governance mechanism influence patterns of individuals' behaviors and interactions differently during knowledge transfer in the Chinese business network.

Finally, we develop a theoretical model to explain how engineers in Chinese SME manufacturers use the functions of guanxi to obtain important information to improve the competitiveness of their firms by integrating different guanxi-based governance mechanisms derived from the combination of different forms of guanxi-enabled trust. Given that guanxi can be considered as a major sociocultural force to influence the individuals' behaviors and interactions in Chinese business networks (Gu et al., 2008; Luo et al., 2011; Yang \& Wang, 2011), our theoretical model adds to a growing body of literature on understanding the influence of sociocultural forces in different countries or region-based business environments (e.g. Alston, 1989; Inkpen \& Pien, 2006; Li et al., 2010; Puffer et al., 2010). Furthermore, the distinction of these forms of guanxi-enabled trust (the foundation of guanxi-based governance mechanisms) is confirmed by exploring the functions of guanxi through different theoretical lenses. Our integrated model of guanxi-based governance mechanisms also addresses calls to incorporate relevant theories into one integrated theory to explain the functions of guanxi in governing individuals' interactions in the Chinese business environment (e.g. Chen \& Chen, 2004; Yang \& Wang, 2011). 


\section{Managerial Implications}

Firstly, our research highlights that knowledge transfer based on interpersonal interactions in the Chinese business environment is still mainly governed by the informal governance mechanisms that derive from the functions of guanxi. This means that the managers (particularly those of foreign firms) interested in improving the innovation capacity of their firm must take steps to learn more about how to use guanxi functions to access knowledge from external sources. On the other hand, managers also need to learn to give others access to knowledge accordingly following the guanxi-based governance mechanisms. The reason is that guanxi-based governance mechanisms are deeply embedded in the Chinese business culture and individuals will be considered to be acting according to their own selfinterest and opportunism in the business community if they do not follow these informal guidelines (Gu et al., 2008; Su et al., 2007; Yang \& Wang, 2011).

Secondly, we have identified different types of guanxi-based governance mechanisms and discussed their characteristics and functions in influencing individuals' behaviors and interactions in Chinese business networks. Managers must understand the importance of these mechanisms and find ways to help their employees to use them to gain access to important knowledge for the benefit of the firm, as well as assist their employees to respond to others' demands for access to the firm's important knowledge. For example, the huibao mechanism emphasizes the reciprocity of exchange. To improve the firms' opportunities to access important knowledge from their employees' network, managers can find ways to assist their employees to return favors to their contacts. One solution might be simply to set up an employee expense allowance to allow employees to withdraw money from the account to buy gifts for their contacts in return for favors. Employees will feel obligated to share the firm's important knowledge with individuals who offer favors to the employees. The same solution can also apply in this situation, as managers can allow employees to withdraw money from 
the allowance expense account to return favors in a way that is unrelated to sharing the firm's important knowledge. Another solution involves establishing an open door policy to invite employees to inform managers when they face this demand. Managers can work with employees to control the content and amount of knowledge that the employees share with others in ways that do not damage the damage the firm's business.

Finally, in our research propositions, we have suggested seven types of guanxi-based governance mechanisms and associated situations. For example, the jiao-qing mechanism is applied when the actors perceive the presence of both guanxi-enabled calculative trust and guanxi-enabled institutional trust simultaneously. Individuals will benefit greatly if they have a strong sensing ability to know what type of mechanism can be used in a specific situation. This is because possessing a strong sensing capability enables individuals to take advantage of guanxi-based governance mechanisms to access important knowledge, as well as respond to other network actors' demands in the appropriate manner. Thus, managers should either adjust the recruitment objective of the firm to hire individuals who already have a great sensing ability regarding guanxi-based governance mechanisms, or organize training and development programs to improve the employees' ability to sense the type of guanxi-based governance mechanisms that exist in different situations.

\section{Limitations and Future Research}

Firstly, the generalizability of the current findings may be regarded as a limitation of this research, which focusses on a single sub-sector in a single industry. Although this focus allows us to explore the ways in which the functions of guanxi promote different forms of guanxi-enabled trust with regard to knowledge transfer, however, it may also hinder our ability to draw broader conclusions across the field. For example, our sample works exclusively in the die-casing sub-sector of the manufacturing industry, and differences between different sub-sector norms may lead to differences in knowledge transfer. Future 
studies conducted on different sub-sectors of the manufacturing industry might help researchers to assess the generalizability of the proposed conceptual framework. Furthermore, the thought process that we employed to investigate the connections among guanxi, the forms of guanxi-enabled trust, and the types of guanxi-based governance mechanisms may also be used to develop an integrated framework that delineates the formation of informal governance mechanisms and identifies how these affect individuals' behaviors and interactions in a network environment beyond the context of Chinese business networks. Future research may employ the same thought process to investigate the functions of other sociocultural-based informal behavioral guiding principles, such as "wa" - Japan, "inhwa" Korea (Alston, 1989), and "blat" - Russia (Puffer et al., 2010), and develop an integrated theory to explain these behavioral-guiding principle-based governance mechanisms in their unique sociocultural-based business environment.

The second limitation concerns the quality of the data. In this research, all of the informants wished to remain anonymous. We were only allowed to take detailed notes during the interviews, not record them verbatim. We tried our best to write everything down that was said during the interviews but, inevitably, we will have missed some of the messages that might have contributed to the research findings. If future researchers have better political connections and increased access to the industry, they may be able to acquire more in-depth information or be granted a more comprehensive study permit. We should also acknowledge the possibility that, if the researchers are too close to their research subjects, they may encounter problems in establishing objectivity, and the permission to record may diminish the informants' willingness to share their opinions and knowledge about this sensitive subject. Thirdly, the design of the study does not take into account the actors' social status, or the strength of the relationships among the actors. This prevents us from undertaking any further comparative analysis of the actors' activities in different settings. Future researchers might 
explore this issue further by comparing how guanxi-based governance mechanisms influence the actors' behaviors and interactions in different settings.

Fourthly, the choice of the qualitative research method may constitute another research limitation. It might help us to build theory about the existing relationships among the variables, but did not enable us to measure the strength of these relationships. Future researchers might develop the measurement of different types of mechanism and test their effectiveness for improving knowledge transfer. This will allow us to further expand the current knowledge about the contribution of guanxi-based governance mechanisms. Finally, a theme of one of our findings, "conflict of interest," describes how actors face a conflict of interest between their loyalty to the firm and their relationship with those in their inner cycle when deciding whether or not to pass on important information to outsiders. Given that such actions may have legal implications, future researchers might want to investigate how individuals make decisions when facing conflicts between following the guidance from guanxi-based governance mechanisms and the legal requirements (formal constraints) in China where the formal constraints might be weak or difficult to enforce (So \& Walker, 2013; Tan et al., 2009; Tsui \& Farh, 1997). Despite these limitations, our research makes important contributions to the literature by incorporating different theoretical dimensions about the functions of guanxi to develop an integrated theory to explain guanxi-based governance mechanisms in the Chinese business environment. We extend the understanding on the formation of guanxi-based governance mechanisms and the influence of such informal mechanisms on knowledge transfer. We hope that further research will continue to explore how the functions of guanxi affect interpersonal and inter-organizational dynamics in Chinese business networks, given China's fast-growing economy and huge market potential for both domestic and foreign firms. 


\section{REFERENCES}

Adler, P. S., \& Kwon, S. W. (2002). Social capital: Prospects for a new concept. Academy of Management Review, 27(1), 17-40.

Alston, J. P. (1989). Wa, guanxi, and inhwa: Managerial principles in japan, china, and korea. Business Horizons, 32(2), 26-31.

Argote, L., \& Ingram, P. (2000). Knowledge transfer: A basis for competitive advantage in firms. Organizational Behavior and Human Decision Processes, 82(1), 150-169.

Argote, L., Ingram, P., Levine, J. M., \& Moreland, R. L. (2000). Knowledge transfer in organizations: Learning from the experience of others. Organizational Behavior and Human Decision Processes, 82(1), 1-8.

Biernacki, P., \& Waldorf, D. (1981). Snowball sampling: Problems and techniques of chain referral sampling. Sociological Methods \& Research, 10(2), 141-163.

Biz China. (2013). Smes become major force in promoting innovation in china. Retrieved from http://news.xinhuanet.com/english/china/2012-06/22/c_131670359.htm (accessed on Aug 2013).

Blumberg, B., Cooper, D. R., \& Schindler, P. S. (2005). Business research methods. Maidenhead, UK: McGraw-hill Education.

Bourdieu, P. (1986). The forms of capital. In J. G. Richardson (Ed.), Handbook of theory and research for sociology of education (pp. 241-258). New York: Greenwood Press.

Buckley, P. J., Clegg, J., \& Tan, H. (2006). Cultural awareness in knowledge transfer to china: The role of guanxi and mianzi. Journal of World Business, 41(3), 275-288.

Burt, R. S. (1992). Structural holes: The social structure of competition. Cambridge, MA: Harvard University Press.

Burt, R. S. (2000). The network structure of social capital. Research in Organizational Behavior, 22(1), 345-423.

Chen, C. H. (1994). Subcontracting networks and social life. Taipai: Lien-Jin Press.

Chen, X. P., \& Chen, C. C. (2004). On the intricacies of the chinese guanxi: A process model of guanxi development. Asia Pacific Journal of Management, 21(3), 305-324.

Cheung, C.-k., \& Gui, Y. (2006). Job referral in china: The advantages of strong ties. Human Relations, 59(6), 847-872.

Child, J., \& Möllering, G. (2003). Contextual confidence and active trust development in the chinese business environment. Organization Science, 14(1), 69-80.

Choi, J. C., Kwon, T. H., Park, J. H., Kim, J. H., \& Kim, C. H. (2002). A study on development of a die design system for diecasting. International Journal of Advanced Manufacturing Technology, 20(1), 1-8.

Chung, H. F. L., Yang, Z., \& Huang, P.-H. (2014). How does organizational learning matter in strategic business performance? The contingency role of guanxi networking. Journal of Business Research, doi:10.1016/j.jbusres.2014.1011.1016.

Coleman, J. S. (1990). Foundations of social theory. Cambridge, MA.: Harvard University Press.

Collinson, S., \& Gregson, G. (2003). Knowledge networks for new technology-based firms: An international comparison of local entrepreneurship promotion. $R \& D$ Management, 33(2), 189-208.

Cook, K. S., Cheshire, C., Rice, E. R. W., \& Nakagawa, S. (2013). Social exchange theory. In J. DeLamater \& A. Ward (Eds.), Handbook of social psychology. New York: Springer.

Corbin, J., \& Strauss, A. (2014). Basics of qualitative research: Techniques and procedures for developing grounded theory. Thousand Oaks: Sage publications.

Cropanzano, R., \& Mitchell, M. S. (2005). Social exchange theory: An interdisciplinary review. Journal of Management, 31(6), 874-900. 
Crouch, C. (2005). Skill formation systems. In S. Ackroyd, R. Batt, P. Thompson \& P. S. Tolbert (Eds.), The oxford handbook of work and organization (pp. 95-114). Oxford: Oxford University Press.

Davidsson, P., \& Honig, B. (2003). The role of social and human capital among nascent entrepreneurs. Journal of Business Venturing, 18(3), 301-331.

Eisenhardt, K. M. (1989). Agency theory: An assessment and review. Academy of Management Review, 14(1), 57-74.

Eloot, K., Huang, A., \& Lehnich, M. (2013). A new era for manufacturing in china. Retrieved from

http://www.mckinsey.com/insights/manufacturing/a_new_era_for_manufacturing_in_ china (accessed on May 2014).

Emerson, R. M. (1976). Social exchange theory. Annual Review of Sociology, 2(1), 335-362.

Etemad, H., \& Lee, Y. (2003). The knowledge network of international entrepreneurship: Theory and evidence. Small Business Economics, 20(1), 5-23.

Fan, Y. (2002). Questioning guanxi: Definition, classification and implications. International Business Review, 11(5), 543-561.

Fisher, K. E., \& Naumer, C. M. (2006). Information grounds: Theoretical basis and empirical findings on information flow in social settings. In A. Spink \& C. Cole (Eds.), New directions in human information behavior (pp. 93-111). Dordrecht: Springer.

Gao, H., Knight, J. G., Yang, Z., \& Ballantyne, D. (2013). Toward a gatekeeping perspective of insider-outsider relationship development in china. Journal of World Business, doi:10.1016/j.jwb.2013.1006.1002.

Gold, T., Guthrie, D., \& Wank, D. L. (2002). Social connections in china: Institutions, culture, and the changing nature of guanxi. Cambridge, U.K.: Cambridge University Press.

Gouldner, A. W. (1960). The norm of reciprocity: A preliminary statement. American Sociological Review, 25(2), 161-178.

Gu, F. F., Hung, K., \& Tse, D. K. (2008). When does guanxi matter? Issues of capitalization and its dark sides. Journal of Marketing, 72(4), 12-28.

Huang, Q., \& Gamble, J. (2011). Informal institutional constraints and their impact on hrm and employee satisfaction: Evidence from china's retail sector. International Journal of Human Resource Management, 22(15), 3168-3186.

Inkpen, A. C., \& Tsang, E. W. K. (2005). Social capital, networks, and knowledge transfer. Academy of Management Review, 30(1), 146-165.

Inkpen, A. C., \& Pien, W. (2006). An examination of collaboration and knowledge transfer: China-singapore suzhou industrial park. Journal of Management Studies, 43(4), 779811.

Jia, F. F., \& Wang, J. J. (2013). Marketing channel relationships in china: A review and integration with an institution-based perspective. Journal of Business Research, 66(12), 2545-2551.

Kato, M., Okamuro, H., \& Honjo, Y. (2015). Does founders' human capital matter for innovation? Evidence from japanese start-ups. Journal of Small Business Management, 53(1), 114-128.

Keil, T., Maula, M., Schildt, H., \& Zahra, S. A. (2008). The effect of governance modes and relatedness of external business development activities on innovative performance. Strategic Management Journal, 29(8), 895-907.

Lee, D. Y., \& Dawes, P. L. (2005). Guanxi, trust, and long-term orientation in chinese business markets. Journal of International Marketing, 13(2), 28-56.

Lee, K. S., \& Luo, C. (2002). Application of case-based reasoning in die-casting die design. International Journal of Advanced Manufacturing Technology, 20(4), 284-295. 
Li, J. J., Poppo, L., \& Zhou, K. Z. (2010). Relational mechanisms, formal contracts, and local knowledge acquisition by international subsidiaries. Strategic Management Journal, 31(4), 349-370.

Lin, N., Ensel, W. M., \& Vaughn, J. C. (1981). Social resources and strength of ties: Structural factors in occupational status attainment. American Sociological Review, 46(4), 393-405.

Lin, N. (2002). Social capital: A theory of social structure and action (Vol. 19). Cambridge: Cambridge University Press.

Locke, K. D. (2001). Grounded theory in management research. Thousand Oaks, CA: SAGE Publications Ltd.

Luo, Y. (1997). Performance implications of international strategy: An empirical study of foreign-invested enterprises in china. Group \& Organization Management, 22(1), 87116.

Luo, Y. (2000). Guanxi and business. Singapore: World Scientific Publishing Company Incorporated.

Luo, Y., Liu, Y., Zhang, L., \& Huang, Y. (2011). A taxonomy of control mechanisms and effects on channel cooperation in china. Journal of the Academy of Marketing Science, 39(2), 307-326.

Luo, Y., Huang, Y., \& Wang, S. L. (2012). Guanxi and organizational performance: A metaanalysis. Management and Organization Review, 8(1), 139-172.

Lüthje, B. (2004). Global production networks and industrial upgrading in china: The case of electronics contract manufacturing. Honolulu, HI: East-West Center.

Muthusamy, S. K., \& White, M. A. (2005). Learning and knowledge transfer in strategic alliances: A social exchange view. Organization Studies, 26(3), 415-441.

NADCA. (2013). About die casting. Retrieved from http://www.diecasting.org/faq/ (accessed on Jan 2013).

Nahapiet, J., \& Ghoshal, S. (1998). Social capital, intellectual capital, and the organizational advantage. Academy of Management Review, 23(2), 242-266.

Orton, J. D., \& Weick, K. E. (1990). Loosely coupled systems: A reconceptualization. Academy of Management Review, 15(2), 203-223.

Owen-Smith, J., \& Powell, W. W. (2004). Knowledge networks as channels and conduits: The effects of spillovers in the boston biotechnology community. Organization Science, 15(1), 5-21.

Park, S. H., \& Luo, Y. (2001). Guanxi and organizational dynamics: Organizational networking in chinese firms. Strategic Management Journal, 22(5), 455-477.

Payne, G. T., Moore, C. B., Griffis, S. E., \& Autry, C. W. (2011). Multilevel challenges and opportunities in social capital research. Journal of Management, 37(2), 491-520.

Peng, M. W., \& Luo, Y. (2000). Managerial ties and firm performance in a transition economy: The nature of a micro-macro link. Academy of Management Journal, 43(3), 486-501.

Peng, M. W. (2002). Towards an institution-based view of business strategy. Asia Pacific Journal of Management, 19(2-3), 251-267.

Peng, M. W., Wang, D. Y. L., \& Jiang, Y. (2008). An institution-based view of international business strategy: A focus on emerging economies. Journal of International Business Studies, 39(5), 920-936.

Phelps, C. C., Heidl, R., \& Wadhwa, A. (2012). Knowledge, networks, and knowledge networks: A review and research agenda. Journal of Management, 38(4), 1115-1166.

Portes, A. (1998). Social capital: Its origins and applications in modern sociology. Annual Review of Sociology, 24(1), 1-24. 
Provan, K. G., \& Kenis, P. (2008). Modes of network governance: Structure, management, and effectiveness. Journal of Public Administration Research and Theory, 18(2), 229252.

Puffer, S. M., McCarthy, D. J., \& Boisot, M. (2010). Entrepreneurship in russia and china: The impact of formal institutional voids. Entrepreneurship Theory and Practice, 34(3), 441-467.

Putnam, R. D. (1993). The prosperous community: Social capital and public life. The American Prospect, 4(13), 35-42.

Qing, X. (2008). The culture relativity in the knowledge flow: An integrative framework in the chinese context. Chinese Management Studies, 2(2), 109-121.

Ramasamy, B., Goh, K. W., \& Yeung, M. C. H. (2006). Is guanxi (relationship) a bridge to knowledge transfer? Journal of Business Research, 59(1), 130-139.

Redding, G., \& Wong, G. Y. Y. (1986). The psychology of chinese organizational behaviour. In M. H. Bond (Ed.), The psychology of the chinese people. New York: Oxford University Press.

Rousseau, D. M., Sitkin, S. B., Burt, R. S., \& Camerer, C. (1998). Not so different after all: A cross-discipline view of trust. Academy of Management Review, 23(3), 393-404.

Scott, W. R. (1994). Institutions and organizations: Toward a theoretical synthesis. Thousand Oaks, CA: Sage.

Shore, L. M., Coyle-Shapiro, J. A. M., Chen, X. P., \& Tetrick, L. E. (2009). Social exchange in work settings: Content, process, and mixed models. Management and Organization Review, 5(3), 289-302.

So, Y. L., \& Walker, A. (2013). Explaining guanxi: The chinese business network. London: Routledge.

Standifird, S. S., \& Marshall, R. S. (2000). The transaction cost advantage of guanxi-based business practices. Journal of World Business, 35(1), 21-42.

Su, C., Mitchell, R. K., \& Sirgy, M. J. (2007). Enabling guanxi management in china: A hierarchical stakeholder model of effective guanxi. Journal of Business Ethics, 71(3), 301-319.

Tan, J., Yang, J., \& Veliyath, R. (2009). Particularistic and system trust among small and medium enterprises: A comparative study in china's transition economy. Journal of Business Venturing, 24(6), 544-557.

Tjosvold, D., Poon, M., \& Yu, Z.-y. (2005). Team effectiveness in china: Cooperative conflict for relationship building. Human Relations, 58(3), 341-367.

Tsang, E. W. K. (1998). Can guanxi be a source of sustained competitive advantage for doing business in china? Academy of Management Executive, 12(2), 64-73.

Tsui, A. S., \& Farh, J. L. (1997). Where guanxi matters relational demography and guanxi in the chinese context. Work and Occupations, 24(1), 56-79.

Wang, H.-K., Tseng, J.-F., \& Yen, Y.-F. (2012). Examining the mechanisms linking guanxi, norms and knowledge sharing: The mediating roles of trust in taiwan's high-tech firms. International Journal of Human Resource Management, 23(19), 4048-4068.

Weick, K. E. (1976). Educational organizations as loosely coupled systems. Administrative Science Quarterly, 21(1), 1-19.

Wu, J. B., Hom, P. W., Tetrick, L. E., Shore, L. M., Jia, L., Li, C., \& Song, L. J. (2006). The norm of reciprocity: Scale development and validation in the chinese context. Management and Organization Review, 2(3), 377-402.

Yang, M. M. (1994). Gifts, favors, and banquets: The art of social relationships in china. Ithaca, N.Y.: Cornell University Press. 
Yang, Z., \& Wang, C. L. (2011). Guanxi as a governance mechanism in business markets: Its characteristics, relevant theories, and future research directions. Industrial Marketing Management, 40(4), 492-495.

Zaheer, A., \& Venkatraman, N. (1995). Relational governance as an interorganizational strategy: An empirical test of the role of trust in economic exchange. Strategic Management Journal, 16(5), 373-392.

Zhao, Z., Anand, J., \& Mitchell, W. (2005). A dual networks perspective on interorganizational transfer of $r \& d$ capabilities: International joint ventures in the chinese automotive industry. Journal of Management Studies, 42(1), 127-160.

Zhao, Z., \& Anand, J. (2009). A multilevel perspective on knowledge transfer: Evidence from the chinese automotive industry. Strategic Management Journal, 30(9), 959-983.

Zhuang, G., Xi, Y., \& Tsang, A. S. L. (2010). Power, conflict, and cooperation: The impact of "guanxi" in chinese marketing channels. Industrial Marketing Management, 39(1), 137-149. 
Figure 1: Data Structure

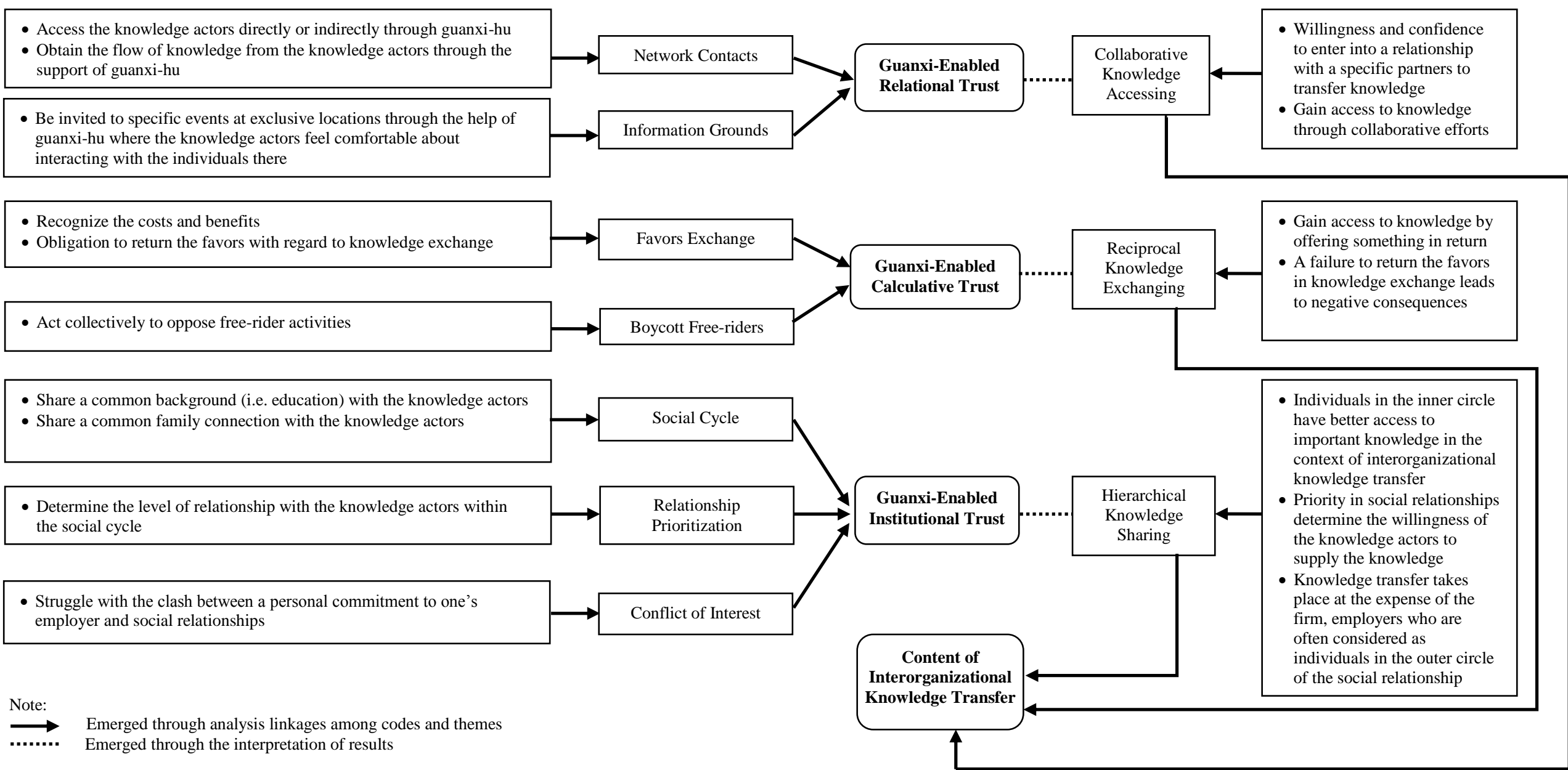


Figure 2: Guanxi Governance Mechanisms

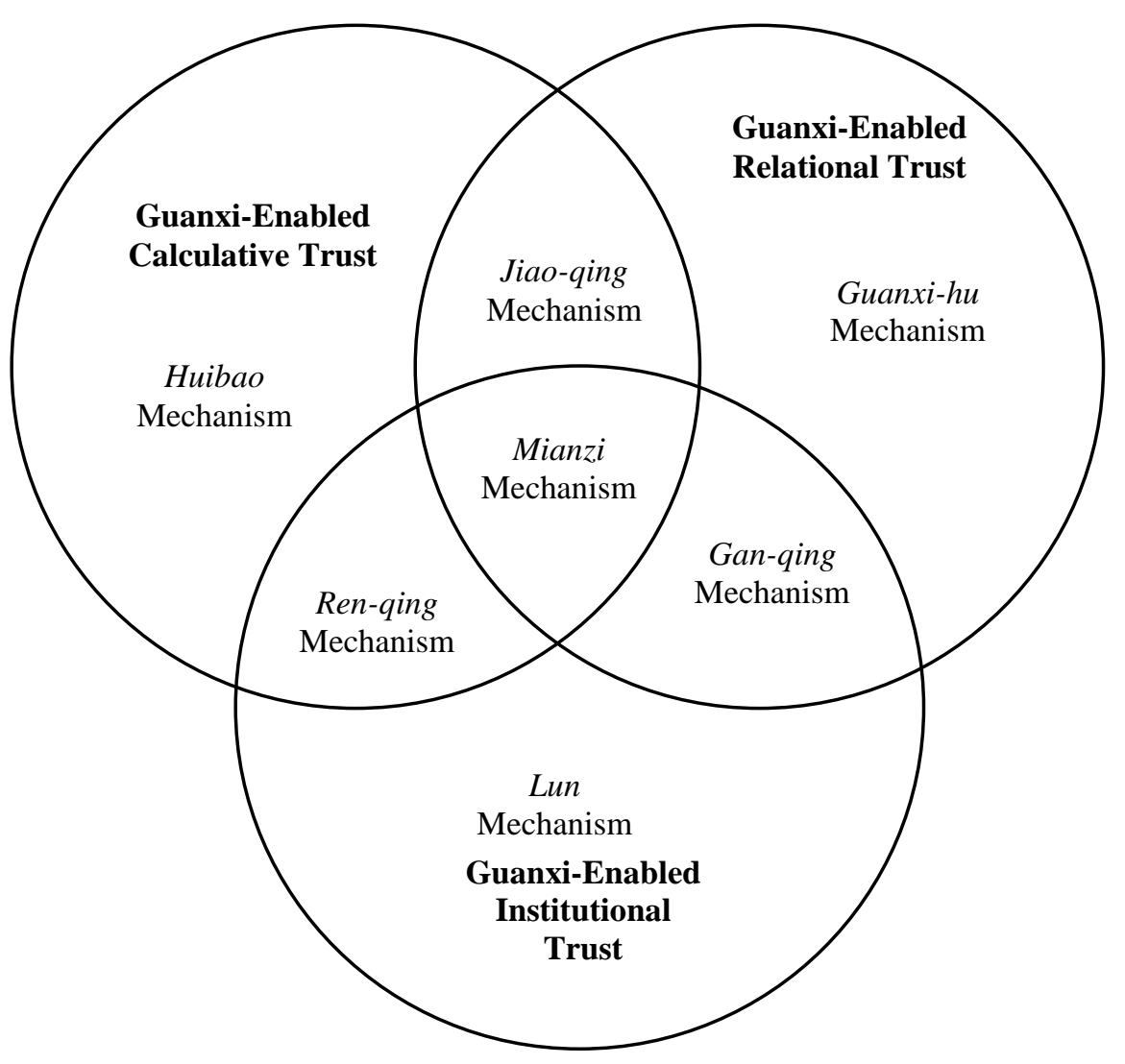

Note:

Figurative usage of terms in Mandarin

- Guanxi-hu: a highly connected individual

- Huibao: reciprocity

- Lun: relationship priority/status hierarchy

- Jiao-qing: the sense of obligation and indebtedness that results from social and economic transactions over a long period

- Ren-qing: the exchange of favors following certain social norms and behavioral rules

- Gan-qing: the emotional attachment among the parties to a network

- Mianzi: the recognition by others of an individual's social status 
Table 1: Data Example for Findings

\begin{tabular}{|c|c|c|c|c|c|c|}
\hline $\begin{array}{l}\text { Aggregate } \\
\text { Theoretical } \\
\text { Dimensions }\end{array}$ & $\begin{array}{l}\text { Second- } \\
\text { Order } \\
\text { Themes }\end{array}$ & $\begin{array}{l}\text { First-Order } \\
\text { Categories }\end{array}$ & Representative Quotations & $\begin{array}{l}\text { First-Order } \\
\text { Categories }\end{array}$ & $\begin{array}{l}\text { Second- } \\
\text { Order } \\
\text { Themes }\end{array}$ & $\begin{array}{l}\text { Aggregate } \\
\text { Theoretical } \\
\text { Dimensions }\end{array}$ \\
\hline \multirow{3}{*}{ 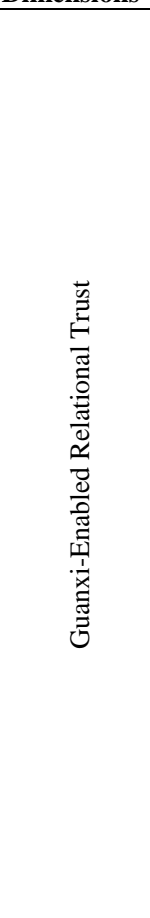 } & \multirow[b]{2}{*}{ 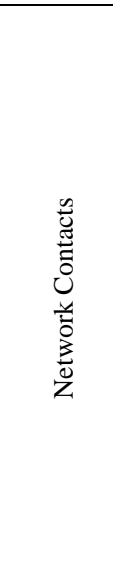 } & $\begin{array}{l}\text { Access to the } \\
\text { knowledge actors } \\
\text { directly or indirectly } \\
\text { through guanxi-hu }\end{array}$ & $\begin{array}{l}\text { - "When I first joined the company after graduating from university, I had little practical experience [about } \\
\text { die-casting mold making], and none of the people [knowledge actors] were willing to help. It took me a long } \\
\text { time to build guanxi by working with and breaking down the wall [gain guanxi-enabled relational trust] with } \\
\text { them. [...] Finally, I was able to learn the real thing [useful techniques for mold making] from them [guanxi- } \\
\text { hu] or they helped me by introducing me to other experts." (Engineer 10)" }\end{array}$ & & \multirow{3}{*}{ 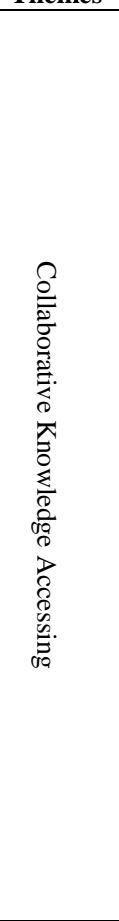 } & \multirow{6}{*}{ 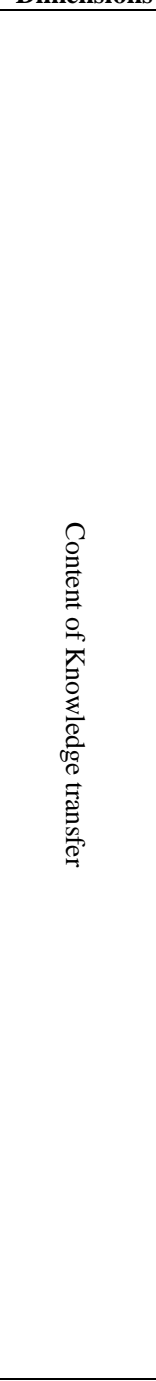 } \\
\hline & & $\begin{array}{l}\text { Obtain the flow of } \\
\text { knowledge from the } \\
\text { knowledge actors } \\
\text { through the support } \\
\text { of guanxi-hu }\end{array}$ & $\begin{array}{l}\text { - "[...] we were looking for a very special technique to do a special surface treatment for a new customer. I } \\
\text { tried many ways to get hold of someone who knew how to do it, but he turned me down because he did not } \\
\text { feel comfortable about helping [a lack of relational trust]. One day, I told my friend [second order guanxi- } \\
\text { hu] about my situation, because he knew many key people [guanxi-hu] in this area. He immediately } \\
\text { introduced me to XXX, who helped us to find an engineer from another factory to help me out and solve my } \\
\text { problems." (Engineer 12) } \\
\text { - "[...] getting in touch with the guanxi-hu [key person] is the key to success. [...]. I remember that, once, we } \\
\text { are working on this new project and I knew whom I should talk to in order to gather more knowledge. After } \\
\text { I made contact with him, he was unwilling to talk because he was worried that I was trying to steal his } \\
\text { clients [a lack of relational trust]. One of my close friends [second order guanxi-hu], luckily, is also a very } \\
\text { close friend of this person [guanxi-hu] so, in the end, I got the knowledge I needed. Without my friend, even } \\
\text { though I knew whom I needed to talk to, I still could not get the necessary knowledge about this project." } \\
\text { (Engineer 52) }\end{array}$ & $\begin{array}{l}\text { Willingness and } \\
\text { confidence to } \\
\text { enter into a } \\
\text { relationship with a } \\
\text { specific partner to } \\
\text { transfer } \\
\text { knowledge }\end{array}$ & & \\
\hline & 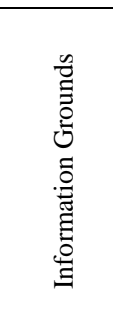 & $\begin{array}{l}\text { Be invited to } \\
\text { specific events at } \\
\text { exclusive locations } \\
\text { through the help of } \\
\text { guanxi-hu where the } \\
\text { knowledge actors } \\
\text { feel comfortable } \\
\text { about interacting } \\
\text { with the individuals } \\
\text { there }\end{array}$ & $\begin{array}{l}\text { - "I have attended many conferences, but the purpose is to meet more people [guanxi-hu] there. The real } \\
\text { [information] exchanges usually take place in private locations, [...], such as at private dinners, games of } \\
\text { golf and ma-jiang matches [a game for four players that originated in China]. [...]. In order to get into these } \\
\text { places, you need to find someone to bring you in. [...] they are usually the ones whom you meet at those } \\
\text { conferences." (Engineer 69) } \\
\text { - "[...] People feel more comfortable with one another [for the purpose of sharing important knowledge] in } \\
\text { specific places [locations or events], such as private clubs or ma-jiang games. [...]. I think that they feel that } \\
\text { the people who are there can be considered as being inside the guanxi circle and, therefore, can be trusted } \\
\text { [guanxi-enabled relational trust]. As a result, usually, these places are exclusive. You need to find someone } \\
\text { [guanxi-hu] who has good guanxi with the event host to bring you in." (Engineer 73) }\end{array}$ & $\begin{array}{l}\text { Gain access to the } \\
\text { knowledge } \\
\text { through } \\
\text { collaborative } \\
\text { efforts }\end{array}$ & & \\
\hline \multirow{3}{*}{ 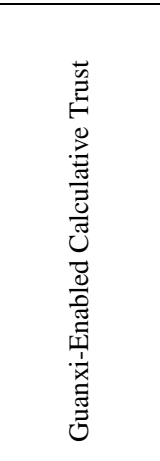 } & \multirow{2}{*}{ 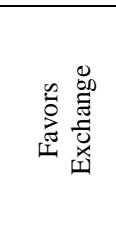 } & $\begin{array}{l}\text { Recognize the costs } \\
\text { and benefits }\end{array}$ & $\begin{array}{l}\text { - "It really comes down to what we can get and how much that we are willing to pay for it [sensible } \\
\text { information]. [...]. Of course, we are not talking about bribery here, but you still need to pay the price in } \\
\text { some other ways such as sharing something [important knowledge] with them later on. [...]." (Engineer, 21) }\end{array}$ & \multirow{2}{*}{$\begin{array}{l}\text { Gain access to the } \\
\text { knowledge by } \\
\text { offering } \\
\text { something in } \\
\text { return }\end{array}$} & \multirow{3}{*}{ 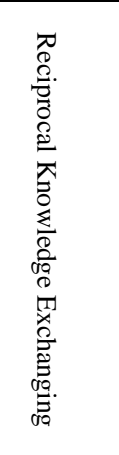 } & \\
\hline & & $\begin{array}{l}\text { Obligation to return } \\
\text { the favors with } \\
\text { regard to knowledge } \\
\text { exchange }\end{array}$ & $\begin{array}{l}\text { - "I will not waste my time on anyone who does not have credibility [calculative trust]. [...]. When people do } \\
\text { not have credibility, they tend to take advantage of me [in the process of social exchange]. [...]. It will cost } \\
\text { us a lot of money and effort to deal with the local authorities to get it straight." (Engineer 41) }\end{array}$ & & & \\
\hline & 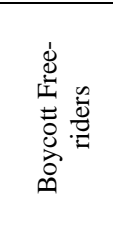 & $\begin{array}{l}\text { Act collectively to } \\
\text { oppose free-rider } \\
\text { activities }\end{array}$ & $\begin{array}{l}\text { - "There is no such thing as a free lunch; you should always return a favor after you receive help [knowledge } \\
\text { transfer] from others, [...]; otherwise, people will not help you again. Moreover, they will tell others, [...], } \\
\text { so you may never receive help from anyone in the circle [network] again, because you do not respect the } \\
\text { rules." (Engineer 29) } \\
\text { - "My friends and I will never help [sharing important knowledge with] someone who we think that will } \\
\text { always try to take advantage in the relationship [fail to return favors]. Furthermore, we will tell our other } \\
\text { friends about this person and persuade them to ignore him/her as well" (Engineer 49) }\end{array}$ & $\begin{array}{l}\text { Failure of } \\
\text { returning the } \\
\text { favors in } \\
\text { knowledge } \\
\text { exchange suffer } \\
\text { consequences }\end{array}$ & & \\
\hline
\end{tabular}




\section{Table 1: Continued}

\begin{tabular}{|c|c|c|c|c|c|c|}
\hline $\begin{array}{l}\text { Aggregate } \\
\text { Theoretical } \\
\text { Dimensions }\end{array}$ & $\begin{array}{l}\text { Second- } \\
\text { Order } \\
\text { Themes }\end{array}$ & $\begin{array}{c}\text { First-Order } \\
\text { Categories } \\
\end{array}$ & Representative Quotations & $\begin{array}{c}\text { First-Order } \\
\text { Categories }\end{array}$ & $\begin{array}{l}\text { Second- } \\
\text { Order } \\
\text { Themes }\end{array}$ & $\begin{array}{c}\text { Aggregate } \\
\text { Theoretical } \\
\text { Dimensions }\end{array}$ \\
\hline \multirow{4}{*}{ 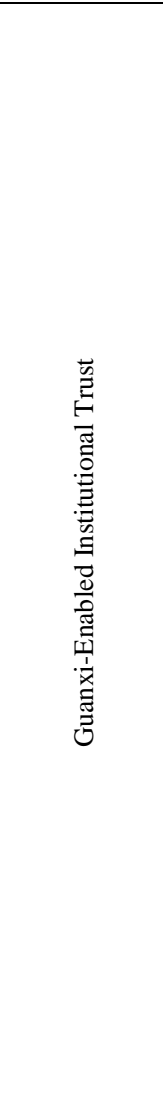 } & \multirow{2}{*}{ 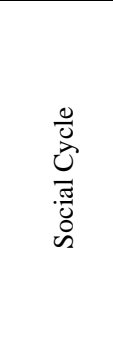 } & $\begin{array}{l}\text { Sharing a } \\
\text { common } \\
\text { background (i.e. } \\
\text { education) with } \\
\text { the knowledge } \\
\text { actors }\end{array}$ & $\begin{array}{l}\text { - "I feel that I was obligated to teach my friend how to perform this task [product design] because we are } \\
\text { tong-xiang [from the same birthplace, a province in northern China] and tong-xue [from the same } \\
\text { university]. I find it very hard to reject a shou-ren [familiar person] like this. [...]. At the same time, I trust } \\
\text { [guanxi-enabled institutional trust] them more then sheng-ren [strangers] whom I don't know much about } \\
\text { it."(Engineer, 57) }\end{array}$ & \multirow{2}{*}{$\begin{array}{l}\text { Individuals in the } \\
\text { inner circle have } \\
\text { better access to } \\
\text { important } \\
\text { knowledge in the } \\
\text { context of } \\
\text { knowledge } \\
\text { transfer }\end{array}$} & \multirow{4}{*}{ 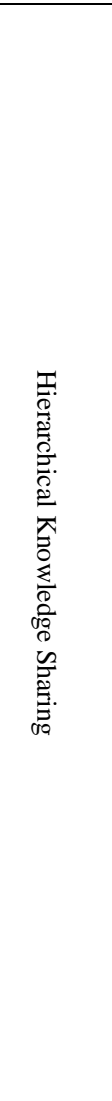 } & \multirow{4}{*}{ 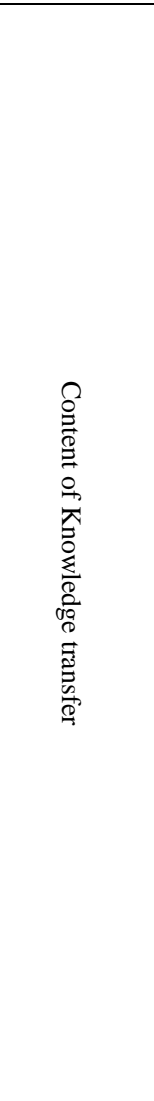 } \\
\hline & & $\begin{array}{l}\text { Sharing a } \\
\text { common family } \\
\text { connection with } \\
\text { the knowledge } \\
\text { actors }\end{array}$ & $\begin{array}{l}\text { "I have more confidence [guanxi-enabled institutional trust] in my family members. I believe that they will } \\
\text { not do some harm to hurt me. Therefore, I am more willing to share my knowledge about the technical } \\
\text { aspects of the project with them and know that they will not pass this knowledge on to my competitors." } \\
\text { (Engineer, 78) }\end{array}$ & & & \\
\hline & 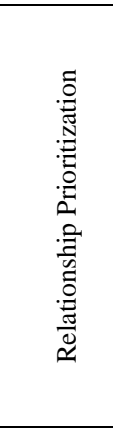 & $\begin{array}{l}\text { Determine the } \\
\text { level of } \\
\text { relationship with } \\
\text { the knowledge } \\
\text { actors within the } \\
\text { social cycle }\end{array}$ & $\begin{array}{l}\text { - "When I face technological questions that I need help with, I will usually ask my jia-ren [family members] } \\
\text { and relatives. If none of them knows how to solve the problem, I will then ask other shou-ren [familiar } \\
\text { people], like tong-xue [from the same educational institution] from my university, or tong-shi [from the } \\
\text { same workplace] but from the same region [tong-xiang]. [...]. The better relationship [strength] that you } \\
\text { have with them, the better help you will get." (Engineer, 24) } \\
\text { - "I consider myself as a leader in my circle [network]. I have been in this industry [die-casting] for years; I } \\
\text { have a high position in the company and a good knowledge of the technological issues. If the tong-xhu } \\
\text { [from a different company] or tong-shi [from the same workplace] in my circle [network] face technical } \\
\text { challenges at work, they will always come to me for help. That's how we look after each other in the same } \\
\text { circle [network]. However, if my jia-ren [family members] or relatives ask me for help, I will be more eager } \\
\text { to help them. [...]. However, if they have a direct conflict [a close competitor, bad relationship] with me, I } \\
\text { will not help them, even if they are my relative, unless they are my own flesh and blood [jia-ren]." } \\
\text { (Engineer, 2) }\end{array}$ & $\begin{array}{l}\text { Priority in social } \\
\text { relationship } \\
\text { determine that } \\
\text { willingness of the } \\
\text { knowledge actors } \\
\text { to supply the } \\
\text { knowledge }\end{array}$ & & \\
\hline & 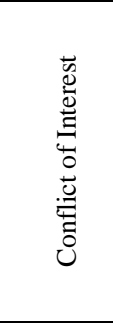 & $\begin{array}{l}\text { Conflict of } \\
\text { Interest }\end{array}$ & $\begin{array}{l}\text {-When my childhood friend asked to me to help him [to teach him the machinery processing skills related to } \\
\text { a specific die-casting part, which can be considered as a competitive edge for my company], I found it very } \\
\text { hard to refuse. We have been looking after each other since we left xxx [their home town] thirteen years ago. } \\
\text { [...]. Losing the only friend I have here [the city] when I am far away from home is a stupid idea." } \\
\text { (Engineer, 62) }\end{array}$ & $\begin{array}{l}\text { Knowledge } \\
\text { transfer takes } \\
\text { place at the } \\
\text { expense of the } \\
\text { firm, employers } \\
\text { who are often } \\
\text { considered as } \\
\text { individuals in the } \\
\text { outer circle of the } \\
\text { social relationship }\end{array}$ & & \\
\hline
\end{tabular}




\section{Table 2: Combination of Guanxi-Enabled Trust - The Qing and the Mianzi Mechanisms}

\begin{tabular}{|c|c|c|}
\hline Combination of Guanxi-Enabled Trust & Guanxi-Enabled Governance Mechanisms & Representative Quotations \\
\hline $\begin{array}{l}\text { Guanxi-enabled relational trust } \\
\text { X } \\
\text { Guanxi-enabled calculative trust }\end{array}$ & Jiao-qing mechanism & $\begin{array}{l}\text { - "I buy gifts for them [guanxi-hu] for different occasions [i.e. Chinese New Year, the mid-autumn festival, birthdays, } \\
\text { etc.], regularly treat them to meals or drinks, and help them to handle personal issues, [...], to develop jiaoqing by } \\
\text { letting them feel that they owe me a lot. Then, it is much easier to ask them for help later on." (Engineer 33) } \\
\text { - "Never expect people [guanxi-hu] to help you [via knowledge transfer] at short notice without good jiaoqing. [...]. } \\
\text { Good jiaoqing takes a long time to build. It is just like a long term investment; you need to put money in and be patient } \\
\text { before you can withdraw a big cheque. If you wait until you have a problem, it is impossible to expect someone to help } \\
\text { you in that case." (Engineer 16) }\end{array}$ \\
\hline $\begin{array}{l}\text { Guanxi-enabled calculative trust } \\
\text { X } \\
\text { Guanxi-enabled institutional trust }\end{array}$ & Ren-qing mechanism & $\begin{array}{l}\text { - "My nephew graduated from a technical institution last year and started a factory with my brother. [...]. If they have } \\
\text { any questions [technical needs], they always come to me [based on renqing] and ask for my help [transfer of } \\
\text { knowledge]. I am the oldest son of the family. It is my responsibility to take care of them. [...]. Although, in most cases, } \\
\text { they insist on offering me something, however, it usually just a small gift to show their appreciation [exchange with } \\
\text { unequal value]." (Engineer, 36) }\end{array}$ \\
\hline $\begin{array}{l}\text { Guanxi-enabled relational trust } \\
\mathrm{X} \\
\text { Guanxi-enabled institutional trust }\end{array}$ & Gan-qing mechanism & $\begin{array}{l}\text { - "[...] if I need to find guanxi-hu to help me to learn new techniques, I will always call on my jia-ren [family members] } \\
\text { first. This is because we have good [strong] ganqing, so I know that they are loyal to me and less likely to take } \\
\text { advantage of me. [...] that is how we take care of each other in all kinds of situation." (Engineer, 65) } \\
\text { - "[...] people usually share knowledge with each other, if they have good [strong] ganqing [i.e. family, friends...]. I tend } \\
\text { to gather a small group of people [with whom I have good guanxi] to form a small circle. Whenever there is new } \\
\text { information [a technique or trick], we will share it with each other within the same circle. [...]. We are very loyal to } \\
\text { each other in this relationship." (Engineer, 35) }\end{array}$ \\
\hline $\begin{array}{l}\text { Guanxi-enabled relational trust } \\
\mathrm{X} \\
\text { Guanxi-enabled calculative trust } \\
\mathrm{X} \\
\text { Guanxi-enabled institutional trust }\end{array}$ & Mianzi Mechanism & $\begin{array}{l}\text { - "Yesterday, I received a phone call from my uncle asking me to share some information about the new surface coating } \\
\text { that our factory uses for a new client. [...]. He asked me to "give him a mianzi" [do him a favor based on his prestige]. I } \\
\text { found it very hard to say no, because he is my uncle [in a higher rank in the relationship hierarchy], I do want to be } \\
\text { regarded as a disrespectful child in my family." (Engineer, 72) } \\
\text { - "You don't always get something back in return immediately after you show others how to solve the problems } \\
\text { [technical]. [...]. If I know that this person is credible [in terms of reciprocity], I will usually not worry that I may not } \\
\text { get any favor in return, as he will not wish to "lose mianzi" over this issue." (Engineer, 3) } \\
\text { - "[...] I have said no often to someone who wanted me to tell them what techniques we use to produce a particular } \\
\text { product for a client. [...]. To persuade me, he asked one of my friends whom I trust very much to convince me. } \\
\text { Eventually, I give up and told him how to do it because of my dear friend's mianzi."(Engineer, 19) }\end{array}$ \\
\hline
\end{tabular}




\section{Appendix 1: Interview Participants}

\begin{tabular}{|c|c|c|c|}
\hline Tynes of Die-Costing Firm & University & $\begin{array}{c}\text { Education } \\
\text { Technical Institution }\end{array}$ & Apprenticeship \\
\hline Die-casting Molding/Tooling & $\begin{array}{l}\# 2(34) ; \# 8(26) ; \# 9(32) ; \# 23(34) ; \# 25(29) ; \# 26(32) ; \\
\# 33(25) ; \# 38(28) ; \# 47(34) ; \# 62(57) ; \# 78(26)\end{array}$ & $\# 31(30) ; \# 40(25)^{*}$ & $\# 39(52) ; \# 51(53)$ \\
\hline Die-casting Part Machinery & $\begin{array}{l}\# 1(33) ; \# 3(27) ; \# 11(27) ; \# 13(31) ; \# 14(40) ; \# 17(39) ; \\
\# 19(30)^{*} ; \# 34(34) ; \# 35(33) ; \# 36(26)^{* ;} \# 37(30) ; \\
\# 42(28) ; \# 43(27) ; \# 44(31) ; \# 45(40) ; \# 46(31) ; \# 48(33) ; \\
\# 49(28) ; \# 57(25) ; \# 63(28) ; \# 64(24)^{*}\end{array}$ & $\# 6(46) ; \# 28(27) ; \# 41(52) ; \# 69(28)^{*} ; \# 71(58)$ & \\
\hline Die-casting Part Subcontractor & $\begin{array}{l}\# 4(24) ; \# 5(31) ; \# 12(35) ; \# 15(36) ; \# 16(36) ; \# 18(48) ; \\
\# 20(30) * ; \# 21(24) * ; \# 22(23) ; \# 29(24)^{*} ; \# 30(24) ; \\
\# 32(25) ; \# 48(32) ; \# 50(48) ; \# 53(24) ; \# 54(28) ; \# 55(38) ; \\
\# 56(30) ; \# 60(45) ; \# 61(30) ; \# 66(24) ; \# 67(35) ; \# 68(35) ; \\
\# 72(30) ; \# 73(32) ; \# 74(28)^{*} ; \# 77(30)\end{array}$ & $\# 7(44) ; \# 27(56) ; \# 47(23)$ & \#65(52); \#75(54) \\
\hline Surface Treatment & $\# 24(27) ; \# 59(36) ; \# 70(34) ; \# 76(31)$ & $\# 52(25) ; \# 58(46)$ & $\# 10(56)$ \\
\hline
\end{tabular}

*Female

Engineer number (\#) are reported (according to the interview order) with age in parathions 


\section{Appendix 2: Data Analysis and Codes}

\begin{tabular}{|c|c|c|}
\hline Data Analysis Stages & Coding Focus & Codes Example \\
\hline \multirow{3}{*}{$\begin{array}{l}\text { Stage 1: The perceptions of relational, calculative, } \\
\text { and institutional trust, that is generated by the use of } \\
\text { guanxi to influence interpersonal interactions }\end{array}$} & $\begin{array}{l}\text { What the respondents said regarding their thoughts and feelings when they evaluate the trust or } \\
\text { trustworthiness based on relationships formed through guanxi (relational trust) }\end{array}$ & $\begin{array}{l}\text { Direct connection; Indirect connection; middle-man; access; } \\
\text { event; location, interactions; etc. }\end{array}$ \\
\hline & $\begin{array}{l}\text { What the respondents said regarding their thoughts and feelings when they evaluate the trust or } \\
\text { trustworthiness based on accessing other actors' intentions and competence in returning favors } \\
\text { in the context of guanxi (calculative trust) }\end{array}$ & $\begin{array}{l}\text { Costs; benefits; favors; obligations; intents; ability; free- } \\
\text { rides; punishments; etc. }\end{array}$ \\
\hline & $\begin{array}{l}\text { What the respondents said regarding their thoughts and feelings when they evaluate the trust or } \\
\text { trustworthiness based on conforming to the social order promoted by guanxi in relation to the } \\
\text { hierarchy of social relationships (institutional trust) }\end{array}$ & $\begin{array}{l}\text { Close relationship; distant relationship; family; colleagues; } \\
\text { friend; supervisor-subordinate; conflicts; rejections; etc. }\end{array}$ \\
\hline $\begin{array}{l}\text { Stage 2: According to the phrases, terms, or } \\
\text { descriptions offered by participants, all revolving } \\
\text { around knowledge transfer }\end{array}$ & $\begin{array}{l}\text { What the respondents said regarding their thoughts and feelings and what they did (or did not } \\
\text { do) in regards to sharing knowledge with actors from other firms }\end{array}$ & $\begin{array}{l}\text { Enter new relationships; existing relationships; } \\
\text { collaboration; exchange; return favors; benefits; } \\
\text { consequences; inner cycle; outer cycle; preferential } \\
\text { treatment; priority; conflict interests; etc. }\end{array}$ \\
\hline
\end{tabular}

